NBER WORKING PAPER SERIES

\title{
THIS IS ONLY A TEST? LONG-RUN IMPACTS OF PRENATAL EXPOSURE TO RADIOACTIVE FALLOUT
}

\author{
Sandra E. Black \\ Aline Bütikofer \\ Paul J. Devereux \\ Kjell G. Salvanes \\ Working Paper 18987 \\ http://www.nber.org/papers/w18987 \\ NATIONAL BUREAU OF ECONOMIC RESEARCH \\ 1050 Massachusetts Avenue \\ Cambridge, MA 02138 \\ April 2013, Revised October 2017
}

\begin{abstract}
We thank Tone D. Bergan at the Norwegian Radiation Protection Authority for providing us with the data she digitalized from the original archives at the Norwegian Defense Research Establishment (FFI), and for her help in clarifying measurement issues. The authors thank the Norwegian Research Council for financial support. We also appreciate comments from presentations at the NBER Summer Institute, Bocconi, Columbia University, MIT, Northwestern University, Boston College, National University of Ireland Maynooth, Oxford University, University of Essex, University of Toronto, Simon Fraser University, Harrison School Chicago University, Northwestern University, Statistics Norway, Stockholm School of Economics, University of Bern, University of British Columbia, University of California Santa Barbara, University of California San Diego, University of St. Gallen, Trinity College Dublin, and a workshop at the Norwegian School of Economics. The views expressed herein are those of the authors and do not necessarily reflect the views of the National Bureau of Economic Research.
\end{abstract}

NBER working papers are circulated for discussion and comment purposes. They have not been peer-reviewed or been subject to the review by the NBER Board of Directors that accompanies official NBER publications.

(C) 2013 by Sandra E. Black, Aline Bütikofer, Paul J. Devereux, and Kjell G. Salvanes. All rights reserved. Short sections of text, not to exceed two paragraphs, may be quoted without explicit permission provided that full credit, including $\odot$ notice, is given to the source. 
This Is Only a Test? Long-Run Impacts of Prenatal Exposure to Radioactive Fallout Sandra E. Black, Aline Bütikofer, Paul J. Devereux, and Kjell G. Salvanes

NBER Working Paper No. 18987

April 2013, Revised October 2017

JEL No. I20,J01,J3

\begin{abstract}
Research increasingly shows that differences in endowments at birth need not be genetic but instead are influenced by environmental factors while the fetus is in the womb. In addition, these differences may persist well beyond childhood. In this paper, we study one such environmental factor - exposure to radiation - that affects individuals across the socio-economic spectrum. We use variation in radioactive exposure throughout Norway in the 1950s and early 60s, resulting from the abundance of nuclear weapon testing during that time period, to examine the effect of nuclear exposure in utero on outcomes such as IQ scores, education, earnings, and adult height, as well as whether these effects persist into the next generation. We find that exposure to low-dose nuclear radiation, specifically during months 3 and 4 in utero, leads to a decline in IQ scores of men aged 18. Moreover, radiation exposure leads to declines in education attainment, high school completion, and earnings among men and women. We are also able to examine whether these effects persist across a second generation. Importantly, we find that the children of persons affected in utero also have lower cognitive scores, suggesting a persistent intergenerational effect of the shock to endowments. Given the lack of awareness about nuclear testing in Norway at this time, our estimates are likely to be unaffected by avoidance behavior or stress effects. These results are robust to the choice of specification and the inclusion of sibling fixed effects.
\end{abstract}

Sandra E. Black

Department of Economics

University of Texas at Austin

Austin, TX 78712

and IZA

and also NBER

sblack@austin.utexas.edu

Aline Bütikofer

Department of Economics

Norwegian School of Economics

Hellev. 30, N-5035 Bergen

Norway

aline.buetikofer@nhh.no
Paul J. Devereux

School of Economics

and Geary Institute

University College Dublin

Belfield, Dublin 4

Ireland

and IZA and CEPR

devereux@ucd.ie

Kjell G. Salvanes

Department of Economics

Norwegian School of Economics

Hellev. 30, N-5035 Bergen

Norway

and IZA and CEPR

kjell.salvanes@nhh.no 


\section{Introduction}

There is a large literature documenting the substantial persistence in early childhood endowments. Increasingly, the evidence shows that differences in endowments at birth need not be genetic but instead are influenced by environmental factors while the fetus is in the womb. This includes studies on the effects of the 1918 flu epidemic (Almond, 2006), the 1957 Asian flu pandemic (Kelly, 2011), the 1959 to 1961 Chinese famine (Almond, Edlund, Li, and Zhang, 2010), the Dutch famine in 1945-46 (Scholte, van den Berg, and Lindeboom 2012), birth weight effects (Black, Devereux and Salvanes, 2007), and the effects of maternal smoking and drinking (Currie, Neidell and Schmieder, 2009; Fertig and Watson, 2009). ${ }^{2}$ In this paper, we study one such environmental factor - exposure to radiation. Importantly, unlike other factors that disproportionately affect one part of society, nuclear exposure affects members of all socioeconomic groups.

This paper uses variation in radioactive exposure throughout Norway in the 1950s and early 1960 s resulting from the extensive nuclear testing during that time period to examine the effect of low-dose nuclear exposure in each month in utero on later-life outcomes such as IQ scores, education, height, and earnings. We then examine the effect of the radiation on IQ scores of the next generation, enabling us to identify the extent to which the shock to endowments persists across generations.

Norway provides an ideal laboratory for this type of analysis; because of its geographical location and topography, with high precipitation in coastal areas, Norway received considerable radioactive fallout from Russian atmospheric nuclear weapons tests in the $1950 \mathrm{~s}$ and $60 \mathrm{~s}$ (Storebø, 1958, Hvinden and Lillegraven, 1961). Regional fallout was determined by wind, rainfall, and topography; we use this variation across Norway and over time for identification.

\footnotetext{
${ }^{2}$ See Currie (2011) for a review.
} 
Since the bombings of Hiroshima and Nagasaki, the effect of nuclear fallout on health and on the cognitive ability of children in utero during the bombings was studied by the medical literature (see, e.g., Otake and Schull, 1984). More closely related on our work are the studies that have examined the impact of the Chernobyl disaster on children who were in utero when it occurred. One important study was by Almond, Edlund and Palme (2009), who find that lowdose exposure in utero leads to lower test scores in school. Our paper adds to this literature by focusing on the long-run effects of low doses of radiation from global nuclear fallout resulting from nuclear weapon testing. Because we are able to incorporate both cross-sectional as well as time-series variation in exposure over a longer period of time, we are able to identify which months of pregnancy are most sensitive to exposure. Finally, we also add to the literature by studying cognitive scores of the second generation (the children of the generation affected in utero) and thus show that there are intergenerational effects of exposure to radiation.

We find that exposure to nuclear fallout in the air or on the ground, even in low doses, leads to a decline in men's IQ scores at age 18, completed years of education, and earnings at age 35. Among women, radiation exposure leads to declines in educational attainment and high school completion, and lower earnings at age 35 . Additionally, there is evidence that the children of the affected generation also have lower cognitive scores, and we are able to calculate the degree of intergenerational transmission. Importantly, we are able to demonstrate that, consistent with the medical literature based primarily on higher doses of radioactive exposure, it is exposure in months 3 and 4 in utero that is most important for low-dose exposure. These results are robust to the choice of specification, tests of selection, and the inclusion of sibling fixed effects.

Unlike the nuclear bombings of Hiroshima and Nagasaki in 1945 and the accident in the nuclear power plant in Fukushima in 2012, there was very little public awareness in Norway of 
the exposure to nuclear fallout resulting from nuclear testing taking place in foreign countries. ${ }^{3}$ Moreover, the first medical studies analyzing the effect of nuclear fallout on cognitive achievement were only published in the 1980s (see, e.g., Otake and Schull, 1984). ${ }^{4}$ Therefore, there is no reason to expect that avoidance behavior is important. This additionally implies that our health effects cannot be explained as resulting from stress due to worry about the effects of radiation. ${ }^{5}$

The paper unfolds as follows. Section II describes the relevant history of nuclear testing affecting Norway. Section III describes our empirical strategy and Section IV describes our data. Section V presents the results for the effects of exposure on children in utero along with a variety of robustness checks, and Section VI presents results for the second generation - the children of these children. Section VII then concludes.

\section{Background}

Nuclear Testing

There was intensive nuclear weapon testing worldwide in the periods $1952-1954,1957-$ 1958, and 1961-1962 (see Appendix Figure A1), with deposition rates peaking in $1963 .^{6}$ According to the United Nations Scientific Committee on the Effects of Atomic Radiation (UNSCEAR), 520 tests were conducted in the atmosphere - most of them prior to 1963. These atmospheric nuclear weapons tests are considered to be the most significant source of radioactive

\footnotetext{
${ }^{3}$ It was not the Norwegian government that established test stations in Norway during the 1950s but the US and British military who were interested in collecting information about test activity in the Soviet Union.

${ }^{4}$ There were indicative studies prior to this suggesting health risks from radiation. However, there was no broad public knowledge about this.

${ }^{5}$ Stress during pregnancy has been linked to poor infant health outcomes (Kuzawa and Sweet, 2009; Black, Devereux, and Salvanes 2013).

${ }^{6}$ On October 10, 1963, a partial test ban treaty came into force, banning nuclear tests in the atmosphere, underwater and in space. The treaty was not signed by France and China; as a result, the last atmospheric explosion was performed by China as late as October 1980.
} 
fallout; contamination resulting from underground nuclear weapon testing is, from a global perspective, negligible.

A nuclear weapon test produces about 150 fission products with half-lives long enough to contribute to radioactive fallout. In general, the fallout can be divided into three components: 1 . large particles that are deposited from the atmosphere within hours of the test, 2. smaller particles that remain in the troposphere only a few days, and 3. longer-lived particles such as Cesium (CS137), Strontium (Str-90), Rubidium (Ru-103), Xenon (Xe-133), Iodine (I-131) and Barium (Ba140), that are injected into the stratosphere (Bergan, 2002). Radioactive debris injected into the stratosphere -- so-called "global fallout" -- trickles down slowly to the troposphere; from there, debris is deposited on the ground mainly through precipitation. Differences in the rate of deposition across locations can thus primarily be explained by temporal and spatial variation in precipitation. Because the fallout cloud disperses with time and distance from the explosion, and radioactivity decays over time, the highest radiation exposures are generally in areas of local fallout. ${ }^{7}$

Immediately following a nuclear explosion, the activity of short-lived radionuclides is much greater than that of long-lived radionuclides. However, the short-lived radionuclides decay substantially during the time it takes the fallout cloud to reach distant locations like Norway, and the long-lived radionuclides become relatively more important. In the polar region, radionuclides remain in the stratosphere on average from 3 to 12 months (UNSCEAR, 1982). ${ }^{8}$ Bergan (2002)

\footnotetext{
${ }^{7}$ According to UNSCEAR (1993) fallout activity deposited close to the test sites accounts for $12 \%$ of total fallout, tropospheric fallout, which is deposited in a band around the globe at the latitude of the test site, for $10 \%$, and global fallout, which is mainly deposited in the same hemisphere as the test site, for $78 \%$. As most tests were carried out in the northern hemisphere, most of the radioactive contamination is also found there.

${ }^{8}$ The polar region is down to the 60 degree latitude (about where Bergen is located in south west Norway), and most of the time the radionuclides from the test sites in Northern Russia were transported in this zone.
} 
estimates the average age of the fallout in Norway to be between 3 and 5 months during the intensive testing periods.

The western Norwegian coast line was particularly exposed to atomic fallout coming from nuclear testing taking place in Novaya Zemlya in the Russian arctic archipelago, one of the most intense test regions between 1955 and 1962. The macro weather system is the primary force that moved long-lived radionuclides from Russian test stations to their ultimate deposition along the Norwegian coast: cold air over the poles creates high pressure zones taking the air to lower latitudes. ${ }^{9}$

Figure 1 shows estimates of the in situ total Beta fallout in each municipality in Norway in $1958,1960,1962$, and $1964 .^{10}$ The activity of fallout in the air or on the ground or other surfaces is measured in becquerels $(\mathrm{Bq})$, which is defined as the number of radioactive disintegrations per second. ${ }^{11}$ The fallout varies significantly by municipality and also over time. There was an international moratorium on nuclear testing from November 1958 to September 1961 so Norway received almost no fallout in the second half of 1959, in 1960, and throughout most of 1961 . The partial test ban treaty in October 1963 led to very little fallout in 1964 or in subsequent years. However, there is significant fallout in 1957 and 1958 and, even more so, in 1962 and 1963 because the explosions after the expiration of the moratorium were much larger than before. This results in substantial time series variation in addition to that across municipalities.

\footnotetext{
${ }^{9}$ Due to the Coriolis forces, the cold dry air moves away from the pole twisting westward resulting in the so-called polar easterlies. Thus, these winds carry air from Northern Russia southwest towards the Norwegian Sea and Iceland. At around 60 degrees north, the airstream enters the low pressure zone and the air is brought eastwards again towards the Norwegian coast. Moreover, the polar jet streams located right below the stratosphere at around 60 degrees north also distributed long-lived nuclear debris over the globe.

${ }^{10}$ We use the phrase "in situ" to denote nuclear fallout that has been deposited to the ground (as distinct from being suspended in the air).

${ }^{11}$ The initial measurements in Norway were made in picoCurie. We have converted these into Bq as this is the current standard unit of measurement.
} 


\section{Prenatal Radiation Exposure and Cognitive Damage}

Following the deposition of fallout into the air and on the ground, there are different means by which people absorb radiation. Irradiation might come from penetrating gamma rays emitted by particles in the air and on the ground. In this case, simply staying inside a building reduces exposure. Moreover, people inhale fallout or absorb it through skin. A further source is the consumption of contaminated food. Vegetation can be contaminated when fallout is directly deposited on the surface of plants, or when it is deposited on the ground and plants absorb it through their roots. People can also be exposed when they eat meat and drink milk from animals grazing on contaminated vegetation or if they drink contaminated water.

It is well-established that ionizing radiation can lead to molecular, cellular, and tissue damage (see, e.g., Hall, 2009). Importantly, actively dividing cells are known to be more sensitive to ionizing radiation than cells that have completed division (see, e.g., ICRP, 1986). As cell cycling and division occur more rapid early in life, the age at the time of exposure to ionizing radiation is an important factor in determining the damage to the developing brain.

While formation of most human organs is largely complete by the 8th week after conception, the development of the cerebral cortex occurs rapidly from weeks 8 to 15 postconception. The neocortex is the part of the cerebral cortex that is involved in higher functions such as sensory perception and generation of conscious thought and language, and medical evidence suggests prenatal exposure to ionizing radiation is particularly harmful if it occurs during this 2-month period of time (see, e.g., Otake and Schull, 1998). By the $16^{\text {th }}$ week of pregnancy, the normal number of neurons in the cerebral neocortex of the human adult has been established (see Dobbing and Sands, 1973). During weeks 16 to 25 after conception, the 
differentiation of cells accelerates, and after the 25th week, the central nervous system becomes quite resistant to radiation. At that point, major fetal brain damage becomes highly improbable (see, e.g. ICRP, 1991; Otake and Schull, 1998).

The first studies indicating that iodizing radiation causes cognitive abnormalities were analyses of individuals exposed in utero to diagnostic X-ray procedures in the 1980s (see, e.g., Brent, 1989). Although quite removed from our framework given the extreme circumstances, most evidence on the effects of acute exposure to ionizing radiation has, however, been obtained from studies on the survivors of the atomic bombs at Hiroshima and Nagasaki. Different studies using a variety of measures of cognitive function, such as the occurrence of severe mental retardation, the intelligence quotient (IQ) and school performance, find a significant effect on individuals exposed during weeks 8 to 15 and weeks 16 to 25 after conception. However, no evidence of a radiation effect has been seen among children exposed prior to the 8th week or subsequent to the 25th week after conception (see, e.g., Otake and Schull, 1984; Otake, Yoshimaru, and Schull, 1989; Miller and Mulvihill, 1956). Moreover, Otake and Schull (1998) report that the risk of severe mental retardation was 5-times greater for persons exposed during weeks 8 to 15 post-conception than for individuals exposed during weeks 16 to 25 postconception.

However, these survivor studies are limited in that they analyze the effects of a single, relatively high dose and not of small, intermittent, or continual doses typical of medical, professional, or environmental exposure. Studies evaluating the impact of smaller doses of radiation, such as those experienced in Sweden after the reactor incident in Chernobyl, on health outcomes such as spontaneous abortion, stillbirth, length of gestation, birth weight, and neonatal mortality, are not conclusive. Some find effects of prenatal exposure, while others do not (see, 
e.g., Lüning et al., 1989; Ericson and Källén, 1994; Sperling et al., 1994; Scherb, Weigelt, and Brüske-Hohlfeld, 1999; Auvinen et al., 2001, Laziuk et al., 2002). However, studies focusing on cerebral dysfunctions do suggest that the prenatal exposure to radioactive fallout after Chernobyl resulted in detectable brain damage or lower schooling performance and fetal death (see, e.g., Nyagu et al., 2004; Almond et al., 2009, Halla and Zweimuller, 2012).

The potential to extrapolate the Japanese or Ukrainian findings to those from the nuclear weapon testing fallout is limited. The global fallout from the testing yielded no fatal doses in Norway, but during periods of the 50s and 60s the population was continuously exposed to radionuclides. In contrast, the Japanese population was acutely irradiated by $\gamma$-rays and neutrons and the Ukrainian population also received a high dose of radioiodine. Because of the different situations, it is not easy to predict the radiobiological effect of the global fallout received by Norway from the Japanese or Ukrainian results. Importantly, unlike most of the literature, we focus on determining the effect of low-dose exposure in each month of pregnancy to empirically determine the timing of exposure that matters. ${ }^{12}$

\section{Empirical Strategy}

To measure the long-run effects of nuclear fallout on cognitive test scores, height, education and income, we exploit the variation in radioactive fallout in Norway within geographic areas over time. We use a similar approach to that in the Chernobyl study of Almond et al. (2009) but incorporate the fact that we have variation over a relatively long period of time

\footnotetext{
${ }^{12}$ Oftedal (1989) evaluates the effect of radiation exposure on scholastic achievement of the 1965 cohort in Norway by hypothesizing that children from the west of Norway should have been more exposed than those from the east and the degree of exposure should vary by season of birth. He compares school test grades from a 10 percent sample of seventh graders in the two regions and finds deviations by region that differ by month-of-birth. He concludes that scholastic achievement is reduced in children exposed in utero to radiation. However, given he studies only one cohort that is born two years after the test-ban treaty, and given that he has no measures of geographic dispersion of radiation, these findings can be viewed as suggestive at best.
} 
as well as across space in order to identify the relevant months of exposure in utero as opposed to picking a predetermined window. The amount of fallout experienced by any individual depends on their month of birth, year of birth, and municipality of birth.

\section{Basic Specification}

We estimate the following equation:

$$
H_{i c t}=\alpha_{0}+\alpha_{1} F_{c t}+\beta X_{i t}+\gamma_{t}+\lambda_{c}+\epsilon_{i c t}
$$

Here $H_{i c t}$ represents outcomes such as education, IQ score, height and earnings for child $i$ born in municipality $c$ at time $t$. We will use the same specification in the intergenerational analysis where $H_{i c t}$ then represents the outcomes of the offspring of the exposed children. $F$ is a vector indicating fallout in each month of pregnancy, beginning 3 months before conception (as a placebo) and ending three months post-birth. $X$ is a vector of controls that includes parental education, the county level unemployment rate when the child was in utero, and birth order indicators (family size at birth of child). We also include controls for year of birth by month of birth indicators $\left(\gamma_{t}\right)$ and municipality fixed effects $\left(\lambda_{c}\right)$; we are therefore comparing individuals born within the same municipality but born in different month/year of birth (and thus exposed to different levels of radiation in utero). ${ }^{13}$ We use OLS estimation; in the case of high school completion, we are estimating a linear probability model.

Specification with Municipality-Specific Trends

\footnotetext{
${ }^{13}$ An alternative to this difference-in-difference type strategy is to use time-series variation in fallout. We have tried this approach by replacing the year of birth by month of birth dummies with a time trend and found effects that have the same sign and statistical significance but smaller magnitudes. Because this is a period of rapid changes in educational infrastructure and in compulsory schooling laws, we have more faith in specifications that include cohort effects.
} 
One concern might be that our results are driven by different trends in municipalities that are exposed to high doses of radiation relative to those that are not. While we examined this directly and found no evidence of differential trends in the observable control variables during this time period, we also report estimates from a specification that allows for municipalityspecific linear trends. ${ }^{14}$ These trends are included in addition to the year of birth by month of birth indicators.

\section{Specification with Interactions}

As a further robustness check, we also estimate a richer model that adds interactions of the municipality dummies with month of birth (to allow for seasonal factors that differ by area) and interactions of the municipality dummies with year of birth (to allow cohort effects to differ by municipality). Note that we cannot include the interaction of year of birth by month of birth by municipality, as that is our identifying variation. Letting $y$ denote year of birth and $m$ denote month of birth, we estimate

$$
H_{i c t}=\alpha_{0}+\alpha_{1} F_{c t}+\beta X_{i t}+\gamma_{t}+\lambda_{c y}+\mu_{c m}+\epsilon_{i c t} .
$$

This model is still well identified as there is much variation in fallout over the course of any particular year that is not driven by seasonal factors but instead by the timing of nuclear tests in the Soviet Union.

\section{Sibling Fixed Effects Model}

While exposure is arguably exogenous to family and neighborhood characteristics within municipalities, one might still worry that non-random migration might change the composition of

\footnotetext{
${ }^{14}$ Results on differential trends for control variables are available from the authors upon request.
} 
people in the municipality over time. Furthermore, the composition of the sample could be correlated with the fallout if there are changes over time and region in the types of people who give birth and these are, by chance, correlated with fallout levels. ${ }^{15}$ While we have no evidence that this is the case, we also estimate a specification that includes sibling fixed effects. Variation is then based on differences in exposure within families across children, thereby differencing out anything that is constant within families such as socio-economic status. ${ }^{16}$

\section{Data}

Data are compiled from a number of different sources. Our primary data source is the Norwegian Registry Data, a linked administrative dataset that covers the population of Norwegians up to 2009 and is a collection of different administrative registers such as the education register, family register, and the tax and earnings register. These data are maintained by Statistics Norway and provide information about educational attainment, labor market status, earnings, and a set of demographic variables (age, gender) as well as information on families. ${ }^{17}$ We include data for cohorts born 1956-1966.

Using month and year of birth, and assuming that a pregnancy lasts 266 days, we can identify the months of pregnancy (ranging from 1-9). Importantly, we assume that exposure to low-dose radiation does not affect the duration of a pregnancy, which is consistent with the findings of the

\footnotetext{
${ }^{15}$ In the U.S., birth selectivity by socio-economic status has been found to differ by month of birth (Buckles and Hungerman, 2010) and by economic conditions (Dehejia and Lleras-Muney, 2004).

${ }^{16}$ Because nuclear radiation may affect later fertility, as a specification check, we have estimated the sibling fixed effects model on a subset where the exposed child is not the first-born and compare this child to existing children and find similar results. We also look at fertility directly and find no effects of exposure on later fertility behavior; this is unsurprising, given the lack of knowledge about exposure at the time.

${ }^{17}$ See Møen, Salvanes and Sørensen (2004) for a description of these data.
} 
Chernobyl study of Almond et al. (2009). ${ }^{18}$ We allocate a municipality to each child born between 1956 and 1964 using the 1960 Census by assuming that the municipality during pregnancy is the mother's municipality of residence in 1960. For individuals born in 1965 and 1966, we are able to use register data on the exact municipality where the mother lived when the child was born.

\section{Military Data}

The IQ score and height data are taken from the Norwegian military records that cover all the cohorts we study. Before young men enter the service, their medical and psychological suitability is assessed; this occurs for the great majority between their eighteenth and twentieth birthday. In Norway, military service is compulsory for every male; as a result, we have military data for men only.

The IQ measure is the mean score from three IQ tests -- arithmetic, word similarities, and figures (see Sundet et al. [2004, 2005] and Thrane (1977) for details). The arithmetic test is quite similar to the arithmetic test in the Wechsler Adult Intelligence Scale (WAIS) (Sundet et al . 2005; Cronbach 1964), the word test is similar to the vocabulary test in WAIS, and the figures test is similar to the Raven Progressive Matrix test (Cronbach 1964). The IQ score is reported in stanine (Standard Nine) units, a method of standardizing raw scores into a nine point standard scale that has a discrete approximation to a normal distribution, a mean of 5, and a standard deviation of $2 .^{19}$

\section{Education}

\footnotetext{
${ }^{18}$ If radiation did decrease gestational length, this would cause us to overestimate the effects of radiation in later months and understate it in earlier months.

${ }^{19}$ The correlation between this IQ measure and the WAIS IQ score has been found to be 0.73 (Sundet et al., 2004).
} 
We measure educational attainment in 2009 and use two measures of education

achievement. High school graduation is an indicator equal to one if the child obtained a threeyear high school diploma. We also consider the years of education completed by the individual.

The data are based on school reports sent directly to Statistics Norway by educational institutions, thereby minimizing any measurement error due to misreporting.

\section{Earnings}

Earnings are measured as annual earnings for taxable income as reported in the tax registry when the individual is aged 35. These are not topcoded and include labor earnings, taxable sick benefits, unemployment benefits, parental leave payments, and pensions. ${ }^{20}$

\section{Data on Nuclear Fallout}

In the period from 1956 to 1984, the Norwegian Defense Research Establishment (FFI) monitored radioactivity in the air and on the ground at 13 stations across Norway. ${ }^{21}$ They collected two primary measures of radiation: (i) a measure of the total beta radiation in the air expressed as $\mathrm{Bq} / \mathrm{m}^{3}$, and (ii) a measure of the total beta radiation in situ (ie on the ground) expressed in $\mathrm{Bq} / \mathrm{m}^{2} .{ }^{22}$ Radioactivity in the air was measured 2 meters above ground level using air filters, and the filters were changed every 24 hours. The samples were sent to the main laboratory of FFI near Oslo, and a Geiger-Müller counter measured the total beta activity 72

\footnotetext{
${ }^{20}$ An individual is labeled as employed if currently working with a firm, on temporary layoff, on up to two weeks of sickness absence, or on maternity leave. We later test the sensitivity of our results to the choice of income measure.

${ }^{21}$ The locations of measurement stations for radioactivity are (from North to South in Norway): Vadsø, Tromsø, Bardufoss, Bodø, Værnes (close to Trondheim in mid Norway), Røros, Ålesund, Bergen, Finse, Sola (close to Stavanger), Gardermoen (close to Oslo), Kjeller (also close to Oslo), Kjevik (close to Kristiansand).

${ }^{22} \mathrm{We}$ obtained the raw data collected for deposition in air and ground measured in picoCurie $/ \mathrm{m}^{3}$ and picoCurie $/ \mathrm{m}^{2}$, respectively. Bergan digitalized the original protocols to obtain the radiation data (Bergan, 2002, 2010, Bergan and Steenhuisen, 2012).
} 
hours after the samples were collected. ${ }^{23}$ Precipitation (rain, snow) and dry particles were also collected at each test station for the measure of ground deposition. ${ }^{24}$ Beta activity came from many isotopes with half-lives of less than a year such as Rubidium (Ru-103), Xenon (Xe-133), Iodine (I-131) and Barium (Ba-140), and also longer-lived ones such as Strontium (Str-90) and Cesium (CS-137), with half-lives of 28 and 30 years respectively.

These two measures of deposition (air and ground) have a correlation coefficient of 0.75 , implying that they are highly -- but far from perfectly -- correlated. Figures $2 \mathrm{a}$ and $2 \mathrm{~b}$ show the two measures for Oslo and Bergen. One can see that the temporal pattern differs for the two measures. This is not surprising as ground deposition is largely determined by rainfall while fallout in the air is more related to the presence of centers of high air pressure as well as influxes of warm subtropical air (Bergan and Steenhuisen, 2012).

There are 13 test stations and about 730 municipalities in Norway during this period. To minimize the measurement error in our measure of nuclear fallout, we limit our sample to municipalities within $20 \mathrm{~km}$ of a test station. ${ }^{25}$ We have tested the sensitivity of our results to different distance cutoffs and find the results are insensitive to this choice.

For radiation in the air, we estimate the fallout for each municipality in our sample in each month by using the fallout at the geographically closest measuring station. For radiation on the ground, we estimate the fallout for each municipality in each month by using the fallout at the geographically closest measuring station and then weight that by the precipitation in that month

\footnotetext{
23 This implies that the short-lived radioisotopes from the decay of Radon had already died out. This is important since Radon is not randomly distributed across regions and its presence might contaminate our estimates of the effects of the fallout from the nuclear tests.

${ }^{24}$ These samples were sent to the same laboratory and total beta activity was measured with the Geiger-Müller counter. In order to identify the source of the radioactive rays, a gamma ray spectrometer was used to identify the different isotopes. See Bergan (2002) for further details about radiation measurement.

${ }^{25}$ See Table 1 for a comparison of our sample to the total population.
} 
in the municipality relative to the precipitation in that month at the measuring station. ${ }^{26}$ This is equivalent to:

$$
F_{c t}=F_{s t} \frac{P_{c t}}{P_{s t}}
$$

where $F_{c t}$ measures the nuclear fallout in municipality $c$ at time $t$ and $F_{s t}$ represents the nuclear fallout at the closest test station $s$ at time $t . P_{i t}$ measures the precipitation in month $t$ in municipality $c$ or $s$. The reason for weighting by the precipitation relative to that at the test station is that the measured ground deposition is already affected by the amount of rain in the test station area. The re-weighting implies that there will be more fallout in areas of relatively heavier rain and less in areas of relatively less rain. ${ }^{27}$

The rain measures come from the Norwegian Meteorological Institute and are available by month for each municipality. The precipitation map of Norway (Figure A2) demonstrates that there are large differences in annual precipitation; precipitation is higher along the west and north coast of the country. Some of the measuring stations along the west coast have more than $3000 \mathrm{~mm}$ average precipitation per year, while other stations measure yearly precipitation of less than $400 \mathrm{~mm}$. This massive variation in rainfall (as shown in Figure A2) is due to the mountain range that divides the country; this resulted in large local variations in deposited radioactivity. ${ }^{28}$

\footnotetext{
${ }^{26}$ Hvinden, Lillegraven and Lillesæter (1965) claim that removal of debris from the troposphere is proportional to precipitation in Norway and tropospheric concentration (see also Lillegraven and Hvinden, 1982). Moreover, Bergan (2002) states that "The fallout is correlated to the amount of precipitation and concentration in air, and the deposited radioactivity is proportional to monthly precipitation." (page 206).

${ }^{27}$ We have also tried using the in situ total beta directly without weighting by the relative rainfall and obtained very similar results. This is unsurprising as we only include municipalities that are within $20 \mathrm{~km}$ of a test station.

${ }^{28}$ Similarly Mattsson and Vesanen (1988) report that $99 \%$ of deposition from Chernobyl in western Sweden was due to rainfall (see Almond et al., 2009).
} 
In Figure $3 \mathrm{a}$ and $3 \mathrm{~b}$ we present the monthly beta fallout at the measuring stations in or close to 5 Norwegian cities from 1956 to $1975 .^{29}$ The figures show substantial variation over time and location.

Summary statistics for our first-generation sample are presented in Table 1a, along with descriptive statistics for the whole country. Because our sample is disproportionately urban, education levels are higher in our sample than in the country as a whole. Table $1 \mathrm{~b}$ presents summary statistics for the sons of the exposed generation (second generation) and describes the sample we use to analyze whether our findings persist into the next generation.

\section{Results-First Generation}

\section{Basic Specification}

We first present the results for IQ scores for men using the two different measures of radiation exposure (in separate regressions), the beta radiation from the air and the in situ, or ground, radiation. For ease of interpretation, when included in regressions, both measures of radioactive exposure are standardized to have mean zero and variance one.

Table 2 presents the results for men when IQ score is the outcome. Each column is a separate regression that includes the standardized measure of exposure in each month of pregnancy, in the 3 months before conception and the 3 months after birth. The first 4 columns present the results using in situ exposure and the second 4 columns use air exposure.

Each regression also includes individual control variables, including indicators for mother's and father's education, birth order controls, and the unemployment rate in the year of

\footnotetext{
${ }^{29}$ There is a measuring station located within the municipality border of Bergen, Røros (central Norway) and Vadsø (northern Norway). The measuring station close to Stavanger is located in the Sola municipality, a neighboring municipality of Stavanger, and is located about $10 \mathrm{~km}$ from the city center of Stavanger. The measuring station in Kjeller is the closest to Oslo and it is about $20 \mathrm{~km}$ away from the city center.
} 
birth in the county of birth. However, the results are insensitive to the inclusion of these controls. ${ }^{30}$ As the IQ score is taken from the Norwegian military records and military service is compulsory only for men, this analysis is restricted exclusively to men. We cluster the standard errors by municipality and so allow arbitrary correlations of the error terms for people born in the same municipality.

Columns 1 and 5 present results from our basic specification that controls for municipality and month of birth by year of birth fixed effects. Columns 2 and 6 then show the results when we add municipality-specific time trends. Columns 3 and 7 present the results from the most saturated model, including municipality-specific month of birth and municipality-specific year of birth controls. In all specifications, we find that radioactive exposure in months 3 and 4 of pregnancy, even the relatively small doses experienced in Norway from the Russian nuclear testing in the 1950s and 1960s, appears to have a significant negative effect on the IQ score of exposed males. This is true regardless of the measure of exposure that we use. To get a sense of the magnitude from the standardized measure, a one standard deviation increase in ground exposure leads to a decline in the IQ score of about 0.04 . Given the standard deviation of the IQ score is about 2 , this is an effect size of about 0.02 of a standard deviation. The effect of air exposure is larger with a one standard deviation increase in exposure leading to about 0.06 of a standard deviation fall in the IQ score. This is equivalent to about 1 IQ point on a standard IQ scale.

The other key finding from this table is that there is no systematic evidence of effects of radiation exposure in any other pregnancy month. One partial exception to this is that there is

\footnotetext{
${ }^{30}$ For parsimony, we don't report results without controls in the tables. These are available from the authors upon request.
} 
some evidence for a smaller adverse effect from radiation in month 5. However, in general, the findings are consistent with adverse effects of radiation being confined to months 3 and 4 .

\section{Sibling Fixed Effects}

We also estimate a specification that includes sibling fixed effects, restricting the sample to families in which there are at least two children born during the period..$^{31}$ The control variables included in these fixed effects estimates are birth order, the unemployment rate, and year of birth by month of birth dummies. These results are presented in Columns 4 and 8 of Table $2 .^{32}$ The sibling fixed effects results are similar to our earlier findings, with IQ score at age 18 significantly affected by exposure in months 3 and 4 but with little evidence of any effects in other months.

\section{Other Outcomes}

Given the robustness of our IQ score results to our choice of specification, the remaining tables present the results from the primary specification that includes both year by month of birth fixed effects and municipality fixed effects.

Tables $3 \mathrm{a}$ and $3 \mathrm{~b}$ present the results for the other outcomes for both men and women (estimated separately) with the two different measures of exposure-Table $3 a$ uses in situ exposure and Table $3 \mathrm{~b}$ uses air exposure. Importantly, it is clear again that it is months 3 and 4 in utero when exposure has a significant effect on education and earnings. When we look at the results for educational attainment and high school completion, we find that radioactive exposure seems to have a negative and statistically significant effect on education among men. Similarly,

\footnotetext{
${ }^{31}$ We also restrict the sample to siblings who were born in the same municipality. This restriction affects very few families and has little impact on the results.

${ }^{32}$ We do not report OLS estimates for the fixed effects sample, but they are similar to those for the full sample.
} 
there is a significantly negative effect of exposure on the educational attainment of women; again, this is robust to the measure of exposure used. The magnitudes suggest that a one standard deviation increase in ground exposure during months 3 and 4 reduces educational attainment by 0.08 years for men and 0.1 years for women, with effects on high school completion of less than 1 percentage point for men and about 1 percentage point for women. We also find statistically significant negative effects on earnings at age 35 for both men and women. ${ }^{33}$

For boys, we can also study height at around age 18. The evidence for adverse effects on height is much weaker, with little evidence of a consistent pattern. These weaker results for height are unsurprising as the scientific research speaks to the effects of radiation on cognitive rather than physical development.

Given that there is no guidance from the medical literature as to the appropriate functional form, we also estimate our results using the log of fallout as the variable of interest. These results are presented in Tables $4 \mathrm{a}$ and $4 \mathrm{~b}$. The same pattern of results emerges with exposure in months 3 and 4 having a negative effect on IQ score, education, and earnings. However, there is no evidence that radiation during these months affects male height. Also, there is little evidence for any effect of radiation during other months on any of the outcomes. The magnitudes are such that a $10 \%$ increase in in situ radiation reduces education by about .01 of a year and decreases earnings by about one fifth of a percentage point.

\section{Further Robustness Checks}

We also conducted a number of further robustness checks. In one case, we include a direct measure of rainfall in addition to the other controls in our regressions. If one worries that it

\footnotetext{
${ }^{33}$ Our findings on educational outcomes are consistent with Oftedal's (1989) results for the effect of radioactive fallout on scholastic achievement at age 14 .
} 
is the rainfall itself, and not the associated fallout, that is driving our results, this would address that concern. (Note that the municipality-specific month of birth effects would likely pick up these effects already, to the extent that this is a seasonal effect.) Not surprisingly, the results are largely unaffected by the inclusion of this variable.

We also tested the sensitivity of our results to the choice of income measure. One might be concerned about the arbitrary nature of our choice of income at age 35 . As a robustness check, we estimated results with the average income between ages 30 and 35 and average income between 35 and 40. The results are very similar.

Finally, we also tried including both measures of fallout (air and ground) in the same regression. For ease of exposition, in the following results, we limit our measure of exposure to the average of that in months 3 and 4 of the pregnancy. These results are presented in Table $5 .{ }^{34}$ Surprisingly given the high correlation between the two measures, we find statistically significant effects for both measures. This suggests that there may be adverse effects both from inhaling radiation from the air, and from ingesting ground radiation through food or water.

\section{Tests for Selection}

One possible selection issue arises if fallout exposure leads to miscarriages, stillbirths, or infant mortality. To the extent that the weakest fetuses are affected, this would tend to lead to an underestimate of the negative effect of exposure. Although there are no birth registers for the cohorts we study, we do have some data that allow us to study whether exposure to radiation affected the probability of survival of children in-utero. Using county-level data (there are 19 counties in Norway) from the Norwegian vital statistics, we find no effects of average radioactive

\footnotetext{
${ }^{34}$ For these and all other results going forward, we are using the original specification with municipality dummies and year of birth by month of birth effects.
} 
fallout in the air or in situ on the live birth/still birth ratio or the gender ratio at birth in that county in that year. This is consistent with the findings of Almond et al. (2009), who found no evidence that the Chernobyl radiation had an impact on birth outcomes in Sweden.

To the extent that radioactive exposure during one pregnancy changes future fertility decisions, estimates of the effects of radioactive exposure (especially those using sibling fixed effects) may be biased. To test for this, we used administrative registry data to examine whether future childbearing decisions were affected by in-utero exposure of existing children. We found that radioactive exposure of the first or second child has no significant effect on completed family size or on later fertility. It is not surprising that we find no evidence of fertility effects, as, at the time, there was no public awareness of the dangers arising from nuclear testing, particularly testing taking place so far away.

\section{Nonlinearities and Heterogeneous Effects}

\section{Quintiles}

While we have already estimated specifications with two different functional forms of the fallout measure, we next examine whether there might be other non-linearities in the effects. To do so, we estimate a specification where we split fallout levels into quintiles. Again, for ease of exposition, we limit our measure of exposure to the average of that in months 3 and 4 . These results are presented in Table 6 using the original specification (with municipality dummies and year of birth by month of birth effects). We find little evidence for non-linearities, in that the estimates are monotonically increasing in magnitude with quintile and it is only for quintiles 3-5 of exposure that there are any significant negative impacts of radioactive fallout. This result is the same for men and women and for both air and ground fallout. 


\section{Varying Intensity of Exposure}

One might expect effects to be larger in months with more sunlight when individuals are more likely to be outside. As another check, we also estimate specifications where we include an interaction indicating whether the exposure (during months 3 and 4 in utero) occurred during spring or summer months (April-September). Table A1 presents these results. We find statistically significant interaction effects for both ground and air fallout, suggesting that exposure is more harmful during spring and summer months.

\section{Family Background}

Finally, the negative effect of poor childhood health on human capital accumulation is often found to be stronger for individuals growing up in a less educated or low-income family (see, e.g., Currie and Hyson, 1999; Currie and Moretti, 2007; Currie, 2011; Almond and Currie, 2010). When we interact the nuclear fallout measures with an indicator variable equal to one if the individual's mother had a high school degree or more, we find that the interaction term is not statistically significant in most cases and the coefficient on the level effect of exposure is quite similar to the earlier estimates (see Table A2). Interestingly, the effect of exposure is actually greater for individuals born to more highly educated parents when we look at years of education for both men and women. This is contrary to what the existing literature would suggest but given the general insignificance of the interaction terms we do not put too much weight on this finding.

\section{Magnitudes}

While what we observe is the nuclear radiation in the environment, the most important issue for health effects is the estimated dose individuals absorb. The basic unit to characterize this type of radiation dose is the Sievert (Sv), which is designed to measure biological effects of 
ionizing radiation. Unfortunately, this dose is very difficult to measure. Bergan and Steenhuisen (2012) estimate that the annual doses of radiation that resulted from the nuclear fallout in Norway in the 1960s were about $23 \mathrm{mSv}$ in Bergen, $5 \mathrm{mSv}$ in Stavanger and $4 \mathrm{mSv}$ in Oslo. To put this into perspective, the external dose received from natural sources of radiation-from primordial radionuclides in the earth's crust and from cosmic radiation - is of the order of $2 \mathrm{mSv}$ per year. The dose from a whole-body computed tomography (CT) examination is about $10 \mathrm{mSv}$, and the external dose from a mammogram breast X-ray is about $0.4 \mathrm{mSv}$.

To get a sense of how our results compare to the existing research, such as that by Almond et al. (2009), it is important to first understand the relative magnitude of the exposure to radioactive fallout. The maximum total beta deposited per month in Norway is lower than the maximum CS-134 fallout in Sweden after Chernobyl. To give a better sense of this: The highest ground deposition of CS-134 Almond et al. (2009) report is $54 \mathrm{kBq} / \mathrm{m}^{2}$. The highest level of monthly total beta fallout reported by the measuring station in Bergen is $32.7 \mathrm{kBq} / \mathrm{m}^{2}$ in January $1962,29.9 \mathrm{kBq} / \mathrm{m}^{2}$ in Kristiansand in October 1961 , and $16.3 \mathrm{kBq} / \mathrm{m}^{2}$ in Trondheim in October 1958. Moreover, the Swedish population was also exposed to other radionuclides in 1986.

While our estimates are not directly comparable to those of Almond et al. (2009), as their main specifications use discrete measures of the degree of exposure of particular regions and they use different measures of radioactive fallout, it is still useful to try to get a sense of relative magnitudes. When they study the effect of log fallout (both air and ground) on compulsory school math scores, they estimate coefficients that are similar in magnitude to the standard deviation of the dependent variable. Our log coefficients for IQ score are about -.04 for ground and about -.25 for air. These are approximately $2 \%$ and $12 \%$ of a standard deviation of the 
dependent variable. This suggests that our magnitudes are much smaller than those of Almond et al. (2009) although they are more precisely estimated. ${ }^{35}$

\section{Results-Second Generation}

Our rich dataset allows us to link across generations and provides a rare opportunity to examine the effects of in-utero exposure to a pollutant on the children of those exposed in utero. ${ }^{36}$ To avoid confusion, we will refer to persons in-utero between 1956 and 1966 as the first generation and refer to their children as the second generation. As mentioned earlier, we have data on IQ test scores for men at age 18/19 up through 2010. This allows us to study the effect of nuclear fallout on IQ for second-generation men (i.e. for sons of the first generation, but not for their daughters).

Of our sample of persons born between 1956 and 1966, 23\% of men and 30\% of women have at least one male child that has taken the military tests by 2010. A likely explanation for this disparity is that women have children at a younger age than men do, increasing their likelihood of having sons who are old enough to be in our sample. ${ }^{37}$

One issue that arises in this analysis is whether there is selection into the sample. To address this, Appendix Table A3 shows that the exposure in pregnancy months 3 and 4 has no effect on the probability of having a son that has taken the military exams by 2010 and thereby on the probability of having a child in the second-generation sample. In addition, we find that the

\footnotetext{
${ }^{35}$ There are multiple reasons why these differences might arise: the age at which the outcome is measured is different, there are differences in the chemical composition of the nuclear fallout, and the estimated specifications differ.

${ }^{36}$ Almond et al. (2010) estimate what they describe as "echo effects" of the 1959-61 Chinese famine on birth weight and sex composition of babies born to women who were in-utero during the famine. We are unaware of any study that has looked at cognitive scores of children born to parents who were exposed to adverse conditions in-utero.

${ }^{37}$ In our sample the mean age at first child is 28.8 for men and 25.9 for women.
} 
fertility behavior (i.e. the probability of having children, number of children, and age at first birth) of the first generation is not affected by the exposure to nuclear fallout.

We report estimates for the second generation for two specifications. The first includes the same control variables that we used when studying outcomes for the first generation. These are pre-determined at the time of the fallout. The second specification includes additional controls for child-specific factors that are likely to have direct effects on IQ scores (family size, birth order, year of birth). While we have found no systematic effects of fallout on fertility behavior of the first generation, there may still be some variation in these control variables that is correlated with exposure of the first generation to radiation. For comparability of the estimates, the regressions are weighted such that each first generation parent gets equal weight. We run separate regressions for the sons of first generation men and women. ${ }^{38}$

It is of some interest to contrast the effect of fallout on IQ scores of the first and second generations. To the extent that radiation exposure mostly affects cognitive function (as is suggested by the medical literature), the ratio of the two effects will approximate the intergenerational transmission coefficient for IQ. A lot is known about intergenerational correlations of IQ scores (see, for example, Black, Devereux and Salvanes (2009) for estimates for Norway), but little is known about causal intergenerational effects of increasing (or reducing) cognitive abilities in one generation. Not all first generation men have sons in our sample so we also include estimates for the IQ scores of the first generation where the sample includes only those men who have sons in our sample. Note that we studied the effects of radiation exposure for both men and women of the first generation but, because our IQ score comes from military

\footnotetext{
${ }^{38}$ We would ideally like to include exposure of both parents in the same regression. Unfortunately, because we only have radiation measurements for municipalities close to measuring stations and for a limited set of cohorts, the radiation data are only available for both parents for a relatively small sample size and estimates are very imprecise.
} 
tests, it is available only for second generation men (i.e. for sons of the first generation but not for their daughters).

Our intergenerational results are in Table $7 \mathrm{a}$ (for in-situ radiation) and Table $7 \mathrm{~b}$ (for radiation in the air). Note again that the results are showing the effect of exposure of parents in utero on the outcomes of their children. Column (1) has results with the same controls as before in the regression for the first generation while column (2) adds the additional second generation controls (year of birth dummies, birth order dummies, and family size). For in-situ radiation, we find statistically significant negative effects of exposure of first generation men in months 3 and 4 in-utero on IQ test scores of the second generation. For women, the effects are also negative and statistically significant for month 4 but not month 3 . The addition of the extra controls in column (2) makes very little difference to the estimates. For exposure through air, the magnitudes are similar but the standard errors are higher so the effects are generally not statistically significant.

In order to compare the effects on the first and second generations, column (3) provides first generation estimates for the common sample of men. Given the imprecision of the estimates for air exposure, we focus on the estimates for in situ radiation in Table 7a. The second generation estimates are about -0.025 ; the first generation ones are about -0.04 . Taken together, these suggest an intergenerational transmission coefficient of about 0.625 . Importantly, this suggests that a large proportion of the adverse cognitive effects of radiation exposure is passed on from fathers to sons.

\section{Conclusion}


A large literature has shown that shocks in utero can have lasting effects on children. In this paper, we study one such environmental factor - exposure to radiation - that affects members of all socioeconomic groups. Using variation in radioactive fallout that was generated by nuclear weapons testing in the northern hemisphere and local differences in precipitation and wind patterns in Norway, we find negative long-run effects of exposure to nuclear fallout on cognitive tests, education, and earnings at age 35 . While the existing literature has suggested that there are effects on cognitive development, we are the first to show that there are other, persistent effects on children's outcomes. In addition, our data also allow us to verify the findings in the medical literature that individuals exposed to radiation during weeks 8 to 16 post conception are the most vulnerable.

Another contribution we make is showing that there are intergenerational effects on cognitive scores for the second generation (the children of persons exposed in utero). Importantly, the initial shock to IQ of men exposed to fallout in utero is passed along to their sons, and the transmission is approximately 0.65 , suggesting very high persistence. As far as we are aware, this is the first causal evidence on the intergenerational transmission of IQ.

Given the lack of knowledge about the fallout in Norway at the time, our estimates are unaffected by avoidance behavior or by maternal stress. Interestingly, and contrary to the existing literature, we find no evidence that high income families are able to offset these negative effects.

While high doses of radiation are rare and confined to persons in the immediate vicinity of nuclear explosions or accidents, lower levels of radiation exposure are more commonplace. ${ }^{39}$ Our

\footnotetext{
${ }^{39}$ In particular, computed tomography (CT) scans are a large source of radioactivity and deliver 100 to 500 times the radiation associated with an ordinary X-ray. The radiation exposure levels of a chest X-ray, for example, are 0.1 $\mathrm{mSv}$, a CT scan of the pelvic or abdomen, however, exposes an individual to about $15 \mathrm{mSv}$. As the fetus is exposed to the radiation dose during a short time interval when the mother receives a CT scan, the treatment should be more
} 
findings of adverse effects on the fetus--even at radiation levels that are too low to make the mother sick--have important potential public policy implications. There is a wide range of possible exposure to anthropogenic releases of radioactivity today: A very recent example is the large amount of radioactivity that was discharged after damage to the cooling systems of several reactors in the Fukushima nuclear power plant in March 2011. Our results suggest that the fluctuating levels of radiation near the malfunctioning nuclear reactors may have had long-term effects on children who were in utero in Fukushima and its adjacent prefectures including Tokyo (see, e.g., Yasunari et al., 2011).

harmful than exposure to similar doses from nuclear fallout from nuclear weapon testing or a power plant accident (Brenner et al., 2003). To put this into perspective, the total dose received people living near the Fukushima Daiichi Nuclear Power Station in Japan during the first four months after the reactors were damaged by a devastating tsunami was about $10 \mathrm{mSv}$ and the average external exposure in Norway from 1955 to 1975 was about 6mSv. Other possible sources of radiation are cosmic radiation during flights (the annual exposure of an airline crew flying New York to Tokyo polar route is about $9 \mathrm{mSv}$ ) or also background radiation from radon gas (about $2 \mathrm{mSv}$ per year). 


\section{Bibliography}

Almond, D. 2006. "Is the 1918 Influenza Pandemic Over? Long-Term Effects of In Utero Influenza Exposure in the Post-1940 U.S. Population." Journal of Political Economy, 114(4): 672-712.

Almond, D.and J. Currie. 2010. "Human Capital Development Before Age Five." In Handbook of Labor Economics. Amsterdam: North-Holland.

Almond, D., L. Edlund and M. Palme. 2009. "Chernobyl's Subclinical Legacy: Prenatal Exposure to Radioactive Fallout and School Outcomes in Sweden." The Quarterly Journal of Economics 124: 1729-1772.

Almond, D., L. Edlund, H. Li, and J. Zhang. 2010. "Long-Term Effects of the 1959-61 China Famine: Mainland China and Hong Kong." In The Economic Consequences of Demographic Change in East Asia, NBER-EASE Vol. 19, ed. T. Ito and A. Rose: 321-350. Chicago: University of Chicago Press.

Auvinen, A., M. Vahteristo, H. Arvela, M. Suomela, T. Rahola, M. Hakama, and T. Rytömaa. 2001. "Chernobyl Fallout and Outcome of Pregnancy in Finland." Environmental Health Perspectives, 109(2): 179-185.

Bergan, T.D. 2002. "Radioactive fallout in Norway from atmospheric nuclear weapons tests." Journal of Environmental Radioactivity, 60(1-2): 189-208.

Bergan, T.D. 2010. "Oversikt over total beta-målinger i luft og nedbør utført ved Forsvarets forskningsinstitutt i perioden 1956-1982." memo, Statens strålevern.

Bergan, T.D. and F. Steenhuisen. 2012. "Deposition of radioactive fallout in Norway due to atmospheric nuclear weapons testing." memo, Norwegian Directorate of Civil Protection and Emergency Planning.

Black, S.E., P.J. Devereux, and K.G. Salvanes. 2007. "From the cradle to the labor market? The effect of birth weight on adult outcomes." Quarterly Journal of Economics, 122: 409-439.

Black, S.E., P.J. Devereux, and K.G. Salvanes. 2009. "Like father, like son? A note on the intergenerational transmission of IQ scores." Economics Letters, 105, 138-140.

Black, S.E., P.J. Devereux, and K.G. Salvanes. 2013. "Does grief transfer across generations? Inutero deaths and child outcomes." Mimeo.

Brenner, D. J., R. Doll, D. T. Goodhead, E. J. Hall, C. E. Land, J. B. Little, J. H. Lubin, D. L. Preston, R. J. Preston, J. S. Puskin, E. Ron, R. K. Sachs, J. M. Samet, R. B. Setlow, and M. Zaider. 2003. "Cancer Risks Attributable to Low Doses of Ionizing Radiation: Assessing What We Really Know." Proceedings of the National Academy of Sciences, 100(13):761-766.

Brent, R.L. 1989. "The effect of embryonic and fetal exposure to x-ray, microwaves, and ultrasound: counseling the pregnant and nonpregnant patient about these risks." Seminars in Oncology, 16(5):347-68.

Buckles, K. and D.M. Hungerman. 2011. "Season of Birth and Later Outcomes: Old Questions, New Answers." NBER Working Papers 14573.

Cronbach, L.J. 1964. Essentials of Psychological Testing, 2nd Edition, London, UK: Harper and Row. 
Currie, J. and E. Moretti. 2007. "Biology as Destiny? Short- and Long-Run Determinants of Intergenerational Transmission of Birth Weight." Journal of Labor Economics 25: 231-263. Currie J, M. Neidell, and J.F. Schmieder. 2009. "Air Pollution and Infant Health: Lessons from New Jersey.” Journal of Health Economics, 28(3); 688-703.

Currie, J. and R. Hyson. 1999. "Is the Impact of Shocks Cushioned by Socioeconomic Status? The Case of Low Birth Weight." American Economic Review, 89: 245-250.

Currie, J. 2011. "Inequality at Birth: Some Causes and Consequences." Ely Lecture. American Economic Review, 101(3): 1-22.

Dehejia, R. and A. Lleras-Muney. 2004. “Booms, Busts, and Babies' Health.” Quarterly Journal of Economics, 119: 1091-1130.

Dobbing, J. and J. Sands. 1973. "Quantitative growth and development of human brain." Archives of Disease in Childhood, 48(10): 757-767.

Ericson, A. and B. Källén. 1994. "Pregnancy Outcome in Sweden after the Chernobyl Accident." Environmental Research, 67: 149-159.

Fertig, A.R. and T. Watson. 2009. "Minimum Drinking Age Laws and Infant Health Outcomes." Journal of Health Economics, 28(3): 737-747.

Hall, E.J. 2009. "Radiation biology for pediatric radiologists." Pediatric Radiology, 39(1): 57-64. Halla, M. and M. Zweimüller. 2012. "The Social Gradient in the Impact of the Chernobyl Accident: The Case of Austria." Working Paper No. 1104, University of Linz.

Hvinden, T. and A. Lillegraven. 1961. "Cæsium-137 and Strontium-90 in precipitation, soil and animals in Norway." Nature 192(4808): 1144-1146.

Hvinden, T., A. Lillegraven, and O. Lillesæter. 1965. "Precipitation as a cause of seasonal and latitudinal variations in radioactive fall-out." Nature, 206(4983), 461-463.

ICRP. 1986. "Developmental effects of irradiation on the brain of the embryo and fetus." A Report of a Task Group of Committee 1 of the International Commission on Radiological Protection. Publication 49, Pergamon Press, Oxford.

ICRP. 1991. "Recommendations of the International Commission on Radiological Protection." International Commission on Radiological Protection, 21(1-3):1-201.

Kelly, E. 2011. " The Scourge of Asian Flu: in utero Exposure to Pandemic Influenza and the Development of a Cohort of British Children." Journal of Human Resources, 46(4), 669-694.

Kuzawa, C. W.and E. Sweet. 2009. "Epigenetics and the Embodiment of Race: Developmental Origins of US Racial Disparities in Cardiovascular Health." American journal of Human Biology, 21: $2-15$.

Laziuk, G. I., I. O. Zatsepin, P. Verger, V. Gagniere, E. Robert, Z. P. Kravchuk, and R. D. Khme. 2002. "Down Syndrome and Ionizing Radiation: Causal Effect or Coincidence." Radiatsionnaia Biologiia, Radioecologiia, 42: 678-683.

Lillegraven, A. and T. Hvinden. 1982. Measurements of cesium-137 in Norwegian soil samples 1960-1979 (in Norwegian with English summary). Norwegian Defence Research Establishment, FFI/Report-82.

Lüning, G., J. Scheer, M. Schmidt, and H. Ziggel. 1989. "Early Infant Mortality in West Germany before and after Chernobyl." Lancet, 8671: 1081-1083.

Mattsson, S. and R. Vesanen. 1988. "Patterns of Chernobyl Rainfall in Relation to Local Weather Conditions." Environment International, 14: 177-180. 
Miller, R.W. and J.W. Mulvihill. 1956. "Small head size after atomic irradiation." Teratology, $14: 355-358$.

Møen, J., K.G. Salvanes, and E.Ø. Sørensen. 2004. "Documentation of the Linked EmpoyerEmployee Data Base at the Norwegian School of Economics." Mimeo, The Norwegian School of Economics and Business Administration.

Nyagu, A. I., K. N. Loganovsky, T. K. Loganovskaja, V. S. Repin, and S. Y. Nechaev. 2004. "Intelligence and Brain Damage in Children Acutely Irradiated in Utero As a Result of the Chernobyl Accident."

Oftedal, P. 1989. "Scholastic achievement in relation to fetal exposure to radioactive fallout in Norway." In Low Dose Radiation, by K. F. Baverstock and J.W. Stather: 323-353. London: Taylor \& Francis.

Otake, M. and W.J. Schull. 1984. "In Utero Exposure to A-Bomb Radiation and Mental Retardation. A Reassessment." British Journal of Radiology 57(677):409-414.

Otake, M. and W.J. Schull. 1998. "Review: Radiation-related Brain Damage and Growth Retardation Among the Prenatally Exposed Atomic Bomb Survivors." International Journal of Radiation Biology, 74(2): 159-171.

Otake, M., H. Yoshimaru, and W.J. Schull. 1989. "Prenatal exposure to atomic radiation and brain damage." Congenital Abnormalities, 29:309-20.

Scherb, H., E. Weigelt, and I. Brüske-Hohlfeld. 1999. "European Still-Birth Proportions before and after the Chernobyl Accident." International Journal of Epidemiology, 28: 932-940.

Scholte, Robert S., Gerard J. van den Berg, and Maarten Lindeboom, 2012. "The Long-Run Effects of Gestation During the Dutch Hunger Winter Famine on Labor Market and Hospitalization Outcomes." IZA Working Paper \#6307, January.

Sperling, K., J. Pelz, R.-D. Wegner, A. Dorries, A. Gruters, and M. Mikkelsen. 1994. "Significant Increase in Trisomy 21 in Berlin Nine Months after the Chernobyl Reactor Accident: Temporal Correlation or Causal Relation?" British Medical Journal,309: 158-162.

Storebø, P. B. 1958. "On nuclear bomb debris deposition in Norway." In Norwegian Defence Research Establishment, Internal Report F-0372. Oslo, Norway.

Sundet, J.M., D.G. Barlaug, and T.M. Torjussen. 2004. "The End of the Flynn Effect? A Study of Secular Trends in Mean Intelligence Test Scores of Norwegian Conscripts During Half a Century." Intelligence , XXXII: 349-362.

Sundet, J.M., K. Tambs, J.R. Harris, P. Magnus, and T.M. Torjussen. 2005. "Resolving the Genetic and Environmental Sources of the Correlation Between Height and Intelligence: A Study of Nearly 2600 Norwegian Male Twin Pairs," Twin Research and Human Genetics, VII: 1-5. Thrane, V.C. 1977. "Evneprøving av Utskrivingspliktige i Norge 1950-53," Arbeidsrapport nr. 26, INAS.

UNSCEAR. 1982. "Ionizing Radiation: Sources and Biological Effects." In United Nations Scientific Committee on the effects of Atomic Radiation. UN, New York.

UNSCEAR. 1993. "The 1993 Report." In United Nations Scientific Committee on the Effects of Atomic Radiation. UN, New York.

Yasunari, T. J., A. Stohl, R.S. Hayano, J.F. Burkhart, S. Eckhardt, T. Yasunari. 2011. "Cesium137 deposition and contamination of Japanese soils due to the Fukushima nuclear accident." Proceedings of the National Academy of Sciences, 108 (49): 19530-19534. 
Figure 1: Total Beta Fallout in situ per Community in 1958, 1960, 1962, and 1964
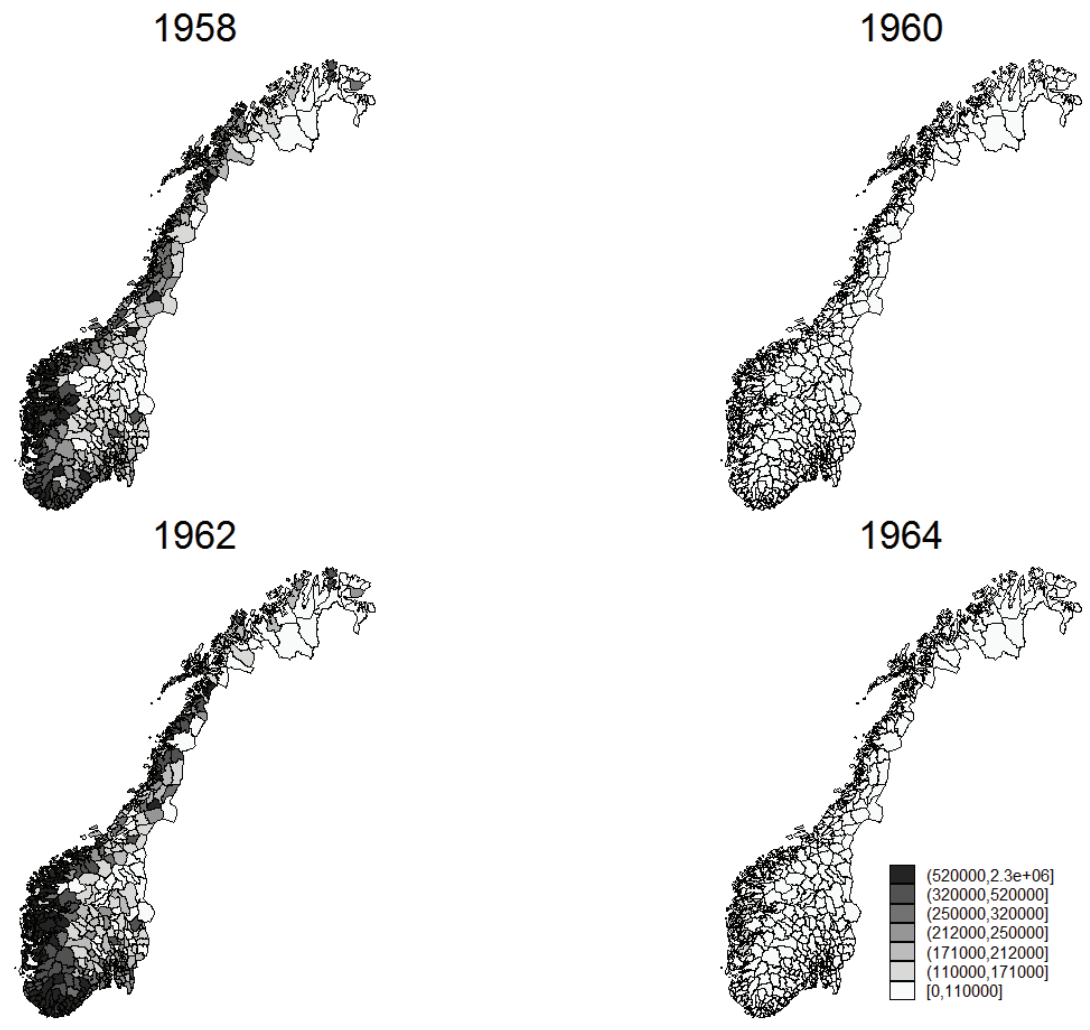

Source: Bergan (2002) 
Figure 2a: Monthly Total Beta Fallout in Oslo (in situ and air).

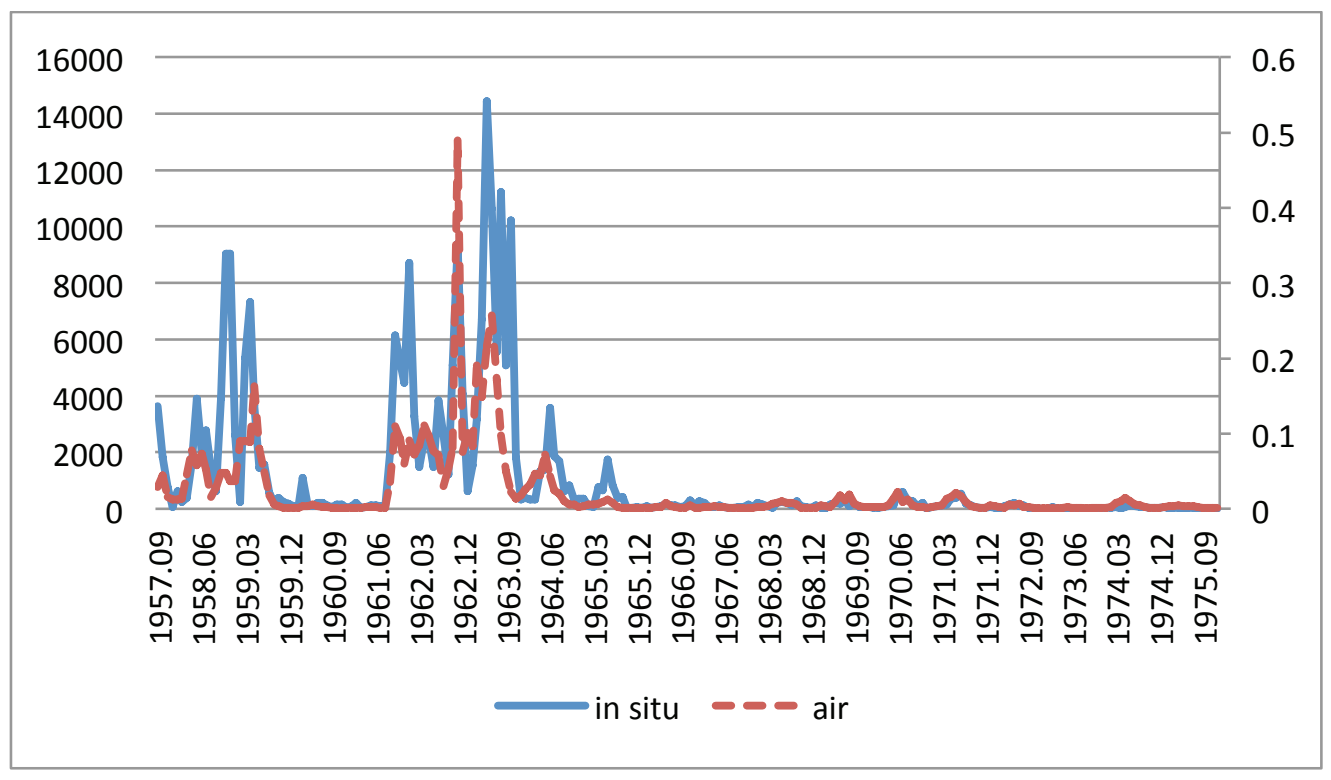

Source: Bergan (2002)

Figure 2b: Monthly Total Beta Fallout in Bergen (in situ and air).

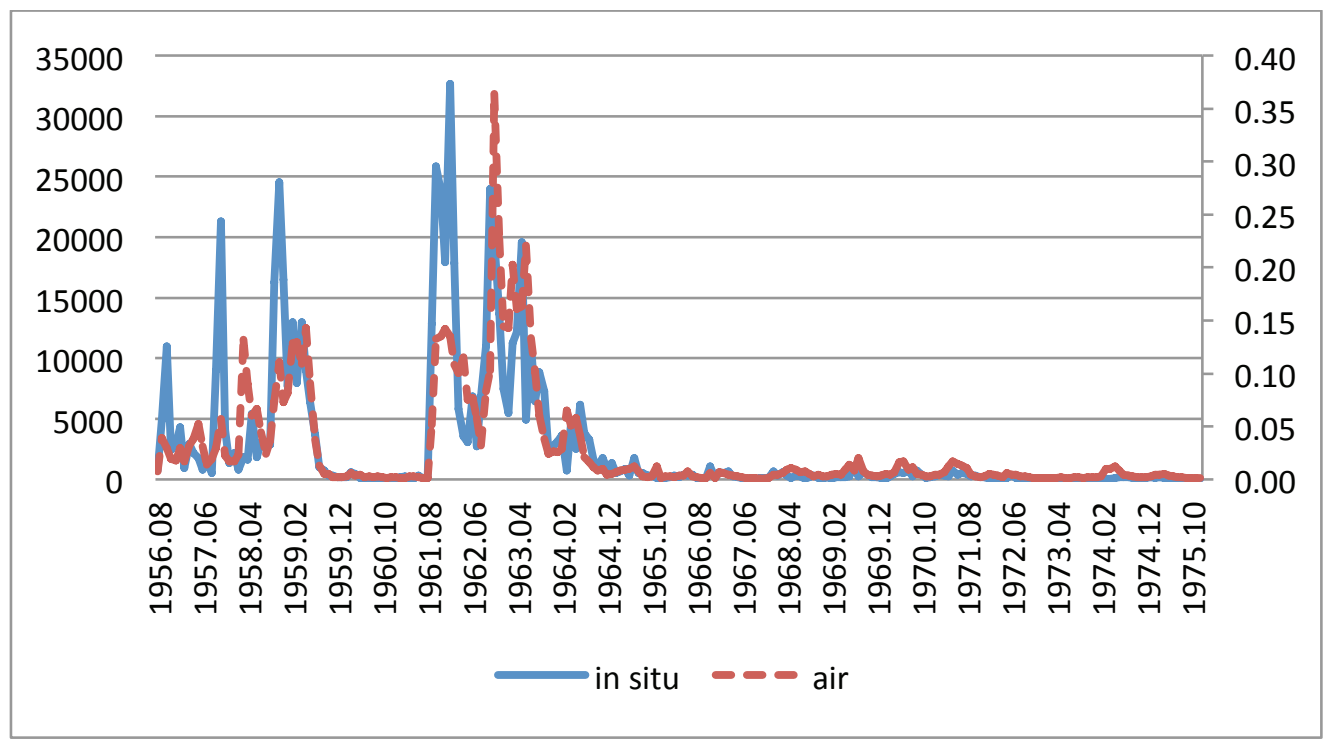

Source: Bergan (2002) 
Figure 3a: Monthly Total Beta in situ fallout in 5 Norwegian cities from 1956 to 1975.

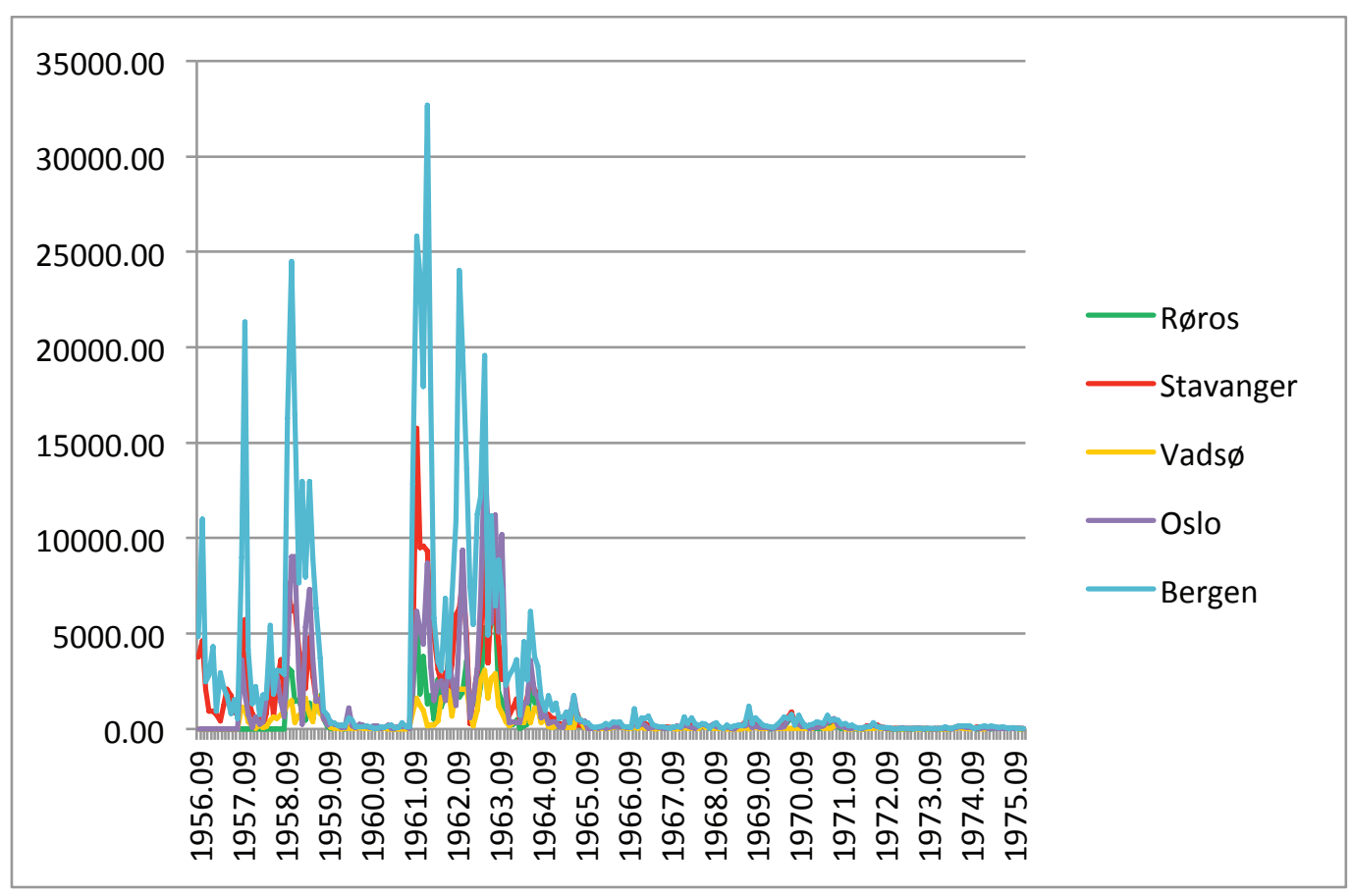

Source: Bergan (2002)

Figure 3b: Monthly Total Beta fallout in air in 5 Norwegian cities from 1956 to 1975.

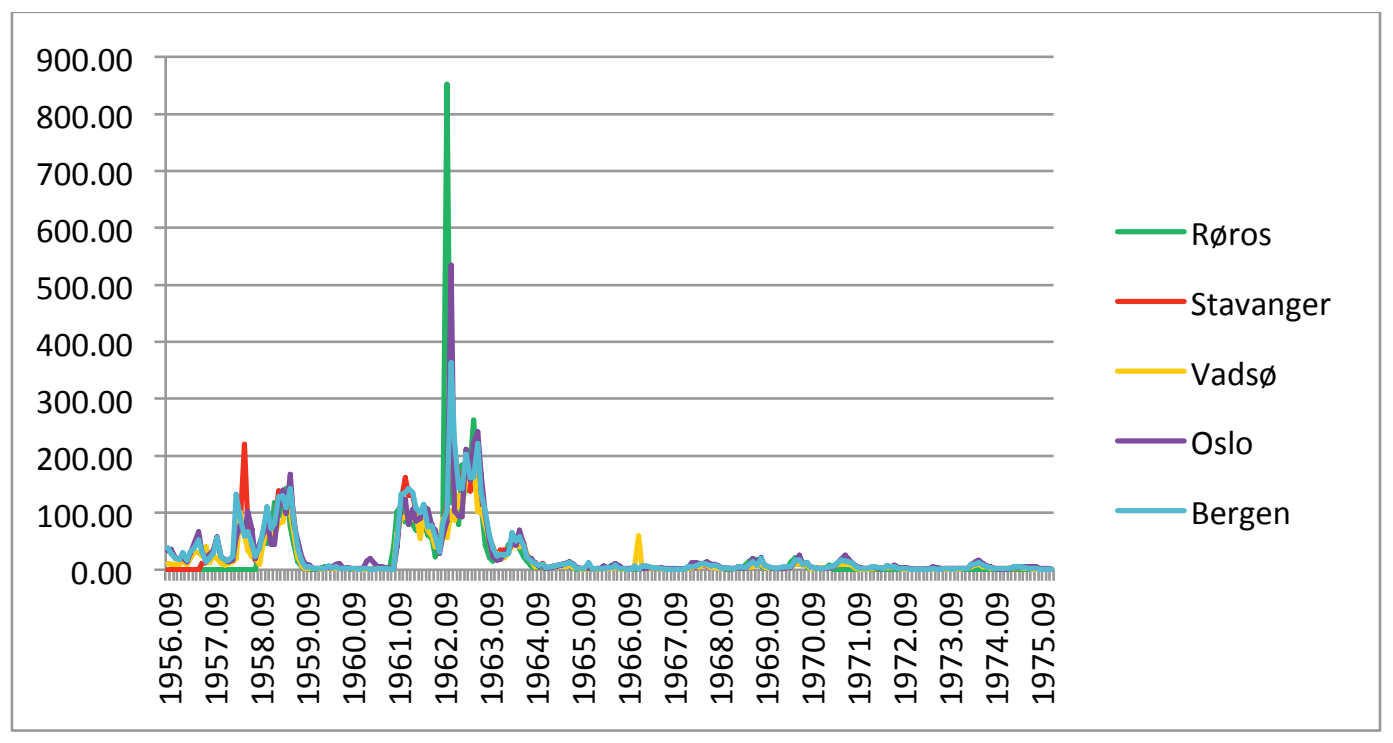

Source: Bergan (2002) 
Table 1a: Summary statistics

\begin{tabular}{|c|c|c|c|c|c|c|c|c|}
\hline & \multicolumn{2}{|c|}{$\begin{array}{c}\text { Men } \\
\text { (20km Sample) }\end{array}$} & \multicolumn{2}{|c|}{$\begin{array}{l}\text { Men } \\
\text { (All) } \\
\end{array}$} & \multicolumn{2}{|c|}{$\begin{array}{c}\text { Women } \\
(20 \mathrm{~km} \text { Sample })\end{array}$} & \multicolumn{2}{|c|}{$\begin{array}{l}\text { Women } \\
\text { (All) }\end{array}$} \\
\hline & Mean & $\begin{array}{l}\text { Standard } \\
\text { deviation }\end{array}$ & Mean & $\begin{array}{l}\text { Standard } \\
\text { deviation }\end{array}$ & Mean & $\begin{array}{l}\text { Standard } \\
\text { deviation }\end{array}$ & Mean & $\begin{array}{l}\text { Standard } \\
\text { deviation }\end{array}$ \\
\hline \multicolumn{9}{|l|}{ Control variables } \\
\hline Father high school degree & 0.425 & 0.494 & 0.301 & 0.458 & 0.417 & 0.493 & 0.296 & 0.457 \\
\hline Mother high school degree & 0.326 & 0.469 & 0.229 & 0.420 & 0.319 & 0.466 & 0.225 & 0.417 \\
\hline Unemployment rate at birth & 0.010 & 0.009 & 0.013 & 0.009 & 0.010 & 0.009 & 0.013 & 0.009 \\
\hline Birth year & 1961 & 3.121 & 1961 & 3.152 & 1961 & 3.169 & 1961 & 3.188 \\
\hline \multicolumn{9}{|l|}{$\begin{array}{l}\text { Radioactive fallout } \\
\text { (months } 3 \text { and } 4 \text { ) }\end{array}$} \\
\hline $\begin{array}{l}\text { Mean monthly. Total Beta air } \\
\left(\mathrm{Bq} / \mathrm{m}^{3}\right)\end{array}$ & 0.042 & 0.059 & & & 0.042 & 0.059 & & \\
\hline $\begin{array}{l}\text { Total month. Total Beta ground } \\
\left(\mathrm{kBq} / \mathrm{m}^{2}\right)\end{array}$ & 2.532 & 3.789 & & & 2.537 & 3.810 & & \\
\hline \multicolumn{9}{|l|}{ Outcome variables } \\
\hline IQ at age 18 (scale: $1-9)$ & 5.264 & 1.995 & 5.011 & 1.999 & & & & \\
\hline Height at age 18 in $\mathrm{cm}$ & 179.7 & 6.376 & 179.4 & 6.387 & & & & \\
\hline Years of education & 12.34 & 2.609 & 12.11 & 2.482 & 12.36 & 2.663 & 12.15 & 2.591 \\
\hline High school completed & 0.731 & 0.443 & 0.714 & 0.452 & 0.682 & 0.466 & 0.653 & 0.476 \\
\hline Earnings at age 35 in NOK & 150146 & 108704 & 140258 & 102672 & 83191 & 59831 & 78658 & 55350 \\
\hline Observations & \multicolumn{2}{|c|}{100354} & \multicolumn{2}{|c|}{297947} & 102373 & & 305347 & \\
\hline
\end{tabular}

Table 1b: Summary Statistics, Second Generation Sons

\begin{tabular}{|c|c|c|c|c|}
\hline & \multicolumn{2}{|c|}{$\begin{array}{c}\text { Fathers } \\
\text { (20km Sample) }\end{array}$} & \multicolumn{2}{|c|}{$\begin{array}{c}\text { Women } \\
\text { (20km Sample) }\end{array}$} \\
\hline & Mean & $\begin{array}{l}\text { Standard } \\
\text { deviation }\end{array}$ & Mean & $\begin{array}{l}\text { Standard } \\
\text { deviation }\end{array}$ \\
\hline \multicolumn{5}{|l|}{ Control variables } \\
\hline Grandfather high school degree & 0.420 & 0.494 & 0.406 & 0.491 \\
\hline Grandmother high school degree & 0.321 & 0.467 & 0.305 & 0.461 \\
\hline $\begin{array}{l}\text { Unemployment rate at birth of } \\
\text { father }\end{array}$ & 0.010 & 0.009 & 0.010 & 0.009 \\
\hline Birth year of father & 1961 & 2.871 & 1961 & 2.879 \\
\hline Birth year & 1985 & 3.191 & 1984 & 3.710 \\
\hline Number of siblings & 1.684 & 0.996 & 1.663 & 0.976 \\
\hline \multicolumn{5}{|l|}{$\begin{array}{l}\text { Father or mothers exposure to } \\
\text { radioactive fallout (months } 3 \\
\text { and } 4 \text { ) }\end{array}$} \\
\hline $\begin{array}{l}\text { Mean monthly. Total Beta air } \\
\left(\mathrm{Bq} / \mathrm{m}^{3}\right)\end{array}$ & 0.043 & 0.059 & 0.042 & 0.055 \\
\hline $\begin{array}{l}\text { Total month. Total Beta ground } \\
\left(\mathrm{kBq} / \mathrm{m}^{2}\right)\end{array}$ & 2.937 & 3.743 & 2.882 & 3.353 \\
\hline \multicolumn{5}{|l|}{ Father's IQ } \\
\hline IQ at age 18 (scale: $1-9)$ & 5.760 & 1.809 & & \\
\hline \multicolumn{5}{|l|}{ Outcome variable } \\
\hline IQ at age 18 (scale: $1-9)$ & 5.014 & 1.682 & 5.054 & 1.690 \\
\hline Observations & \multicolumn{2}{|c|}{24281} & \multicolumn{2}{|c|}{36947} \\
\hline
\end{tabular}




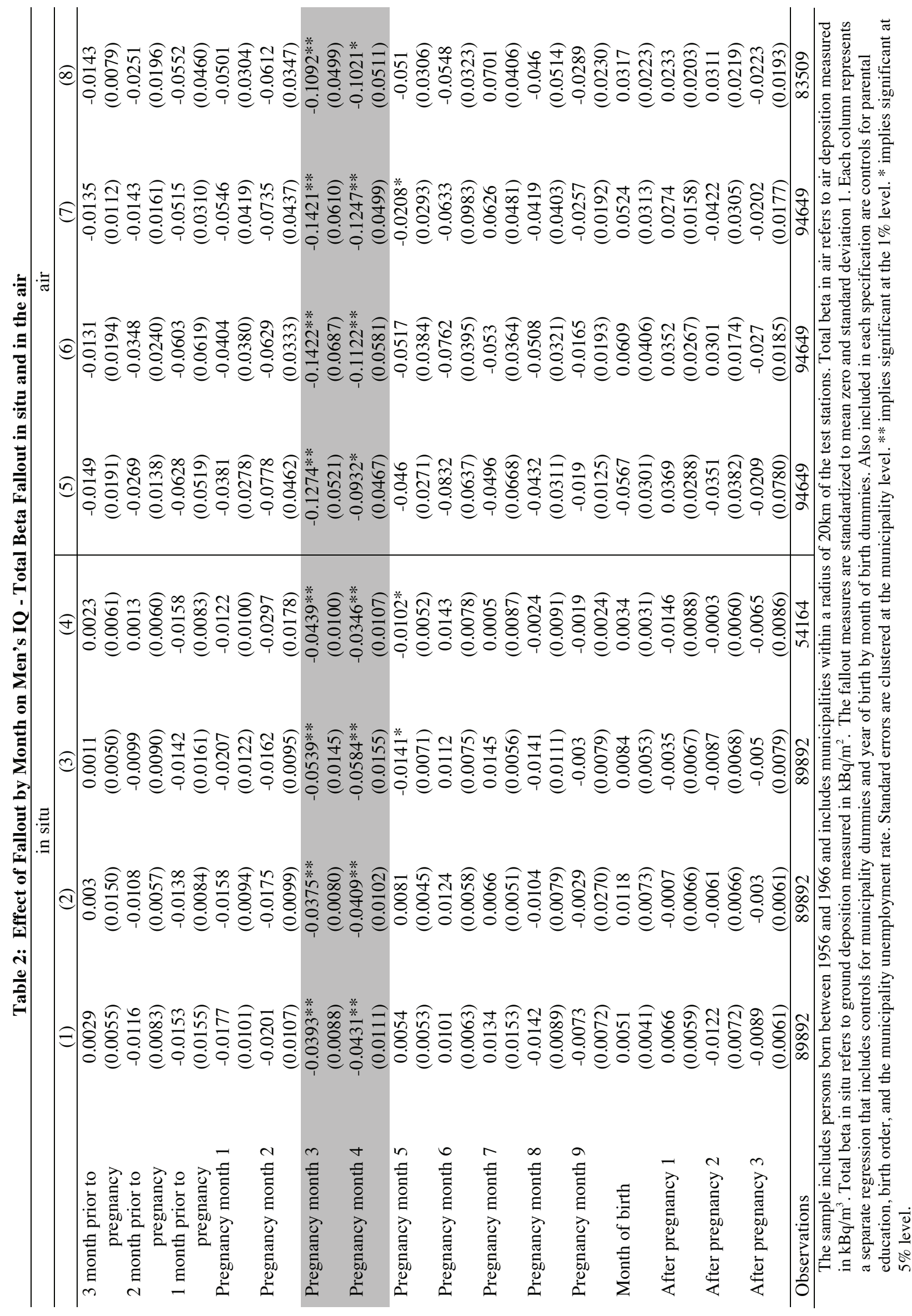




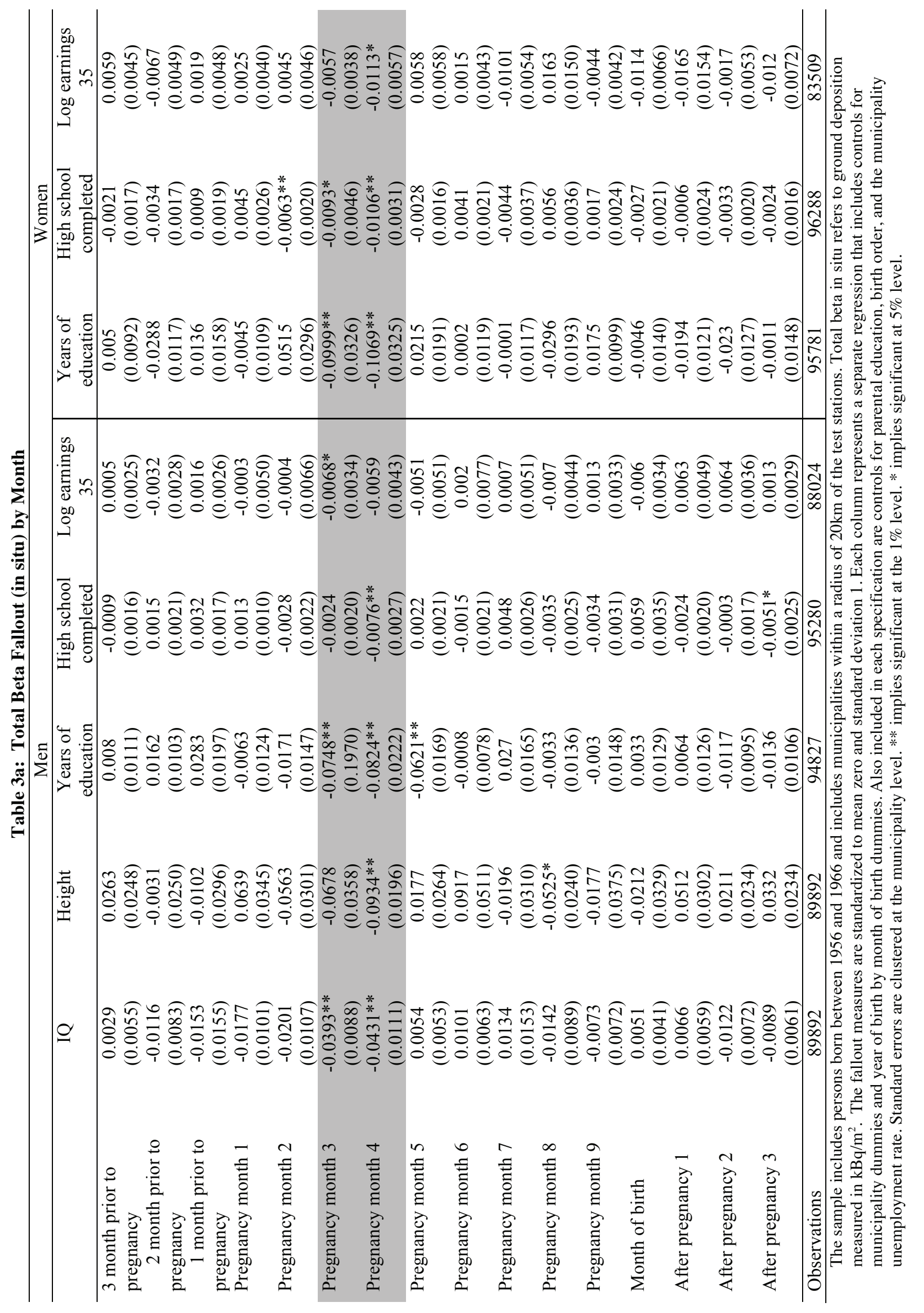




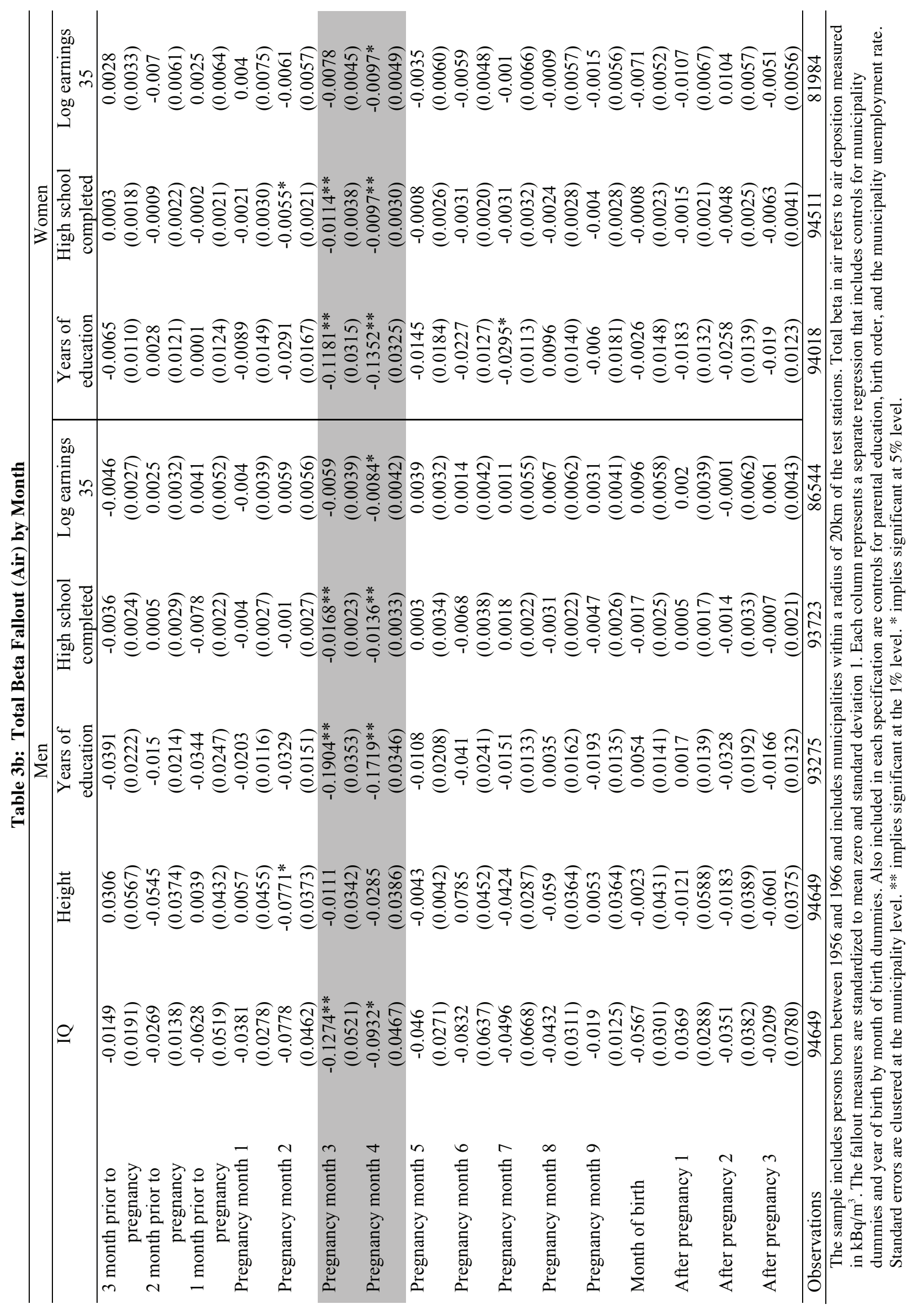




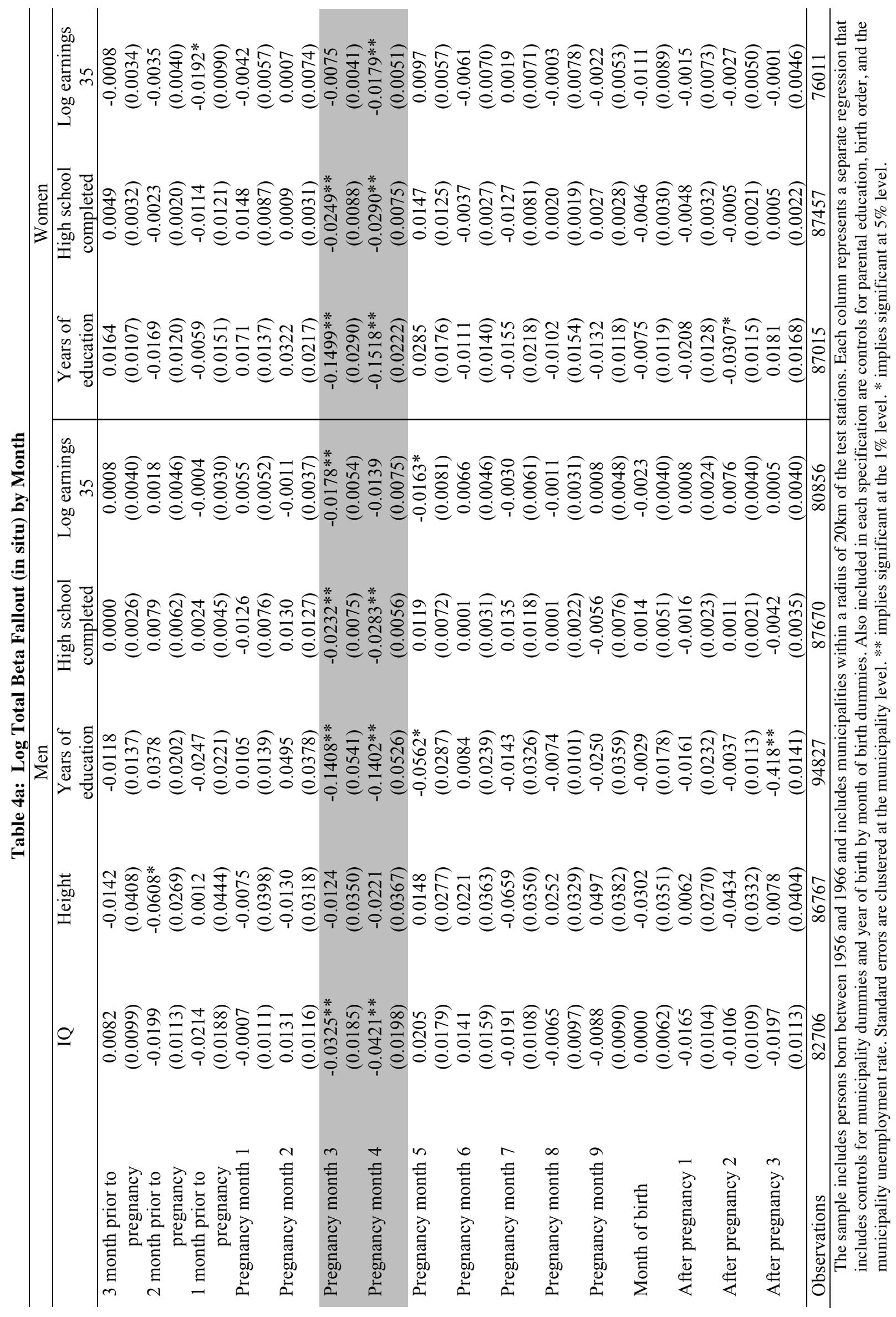




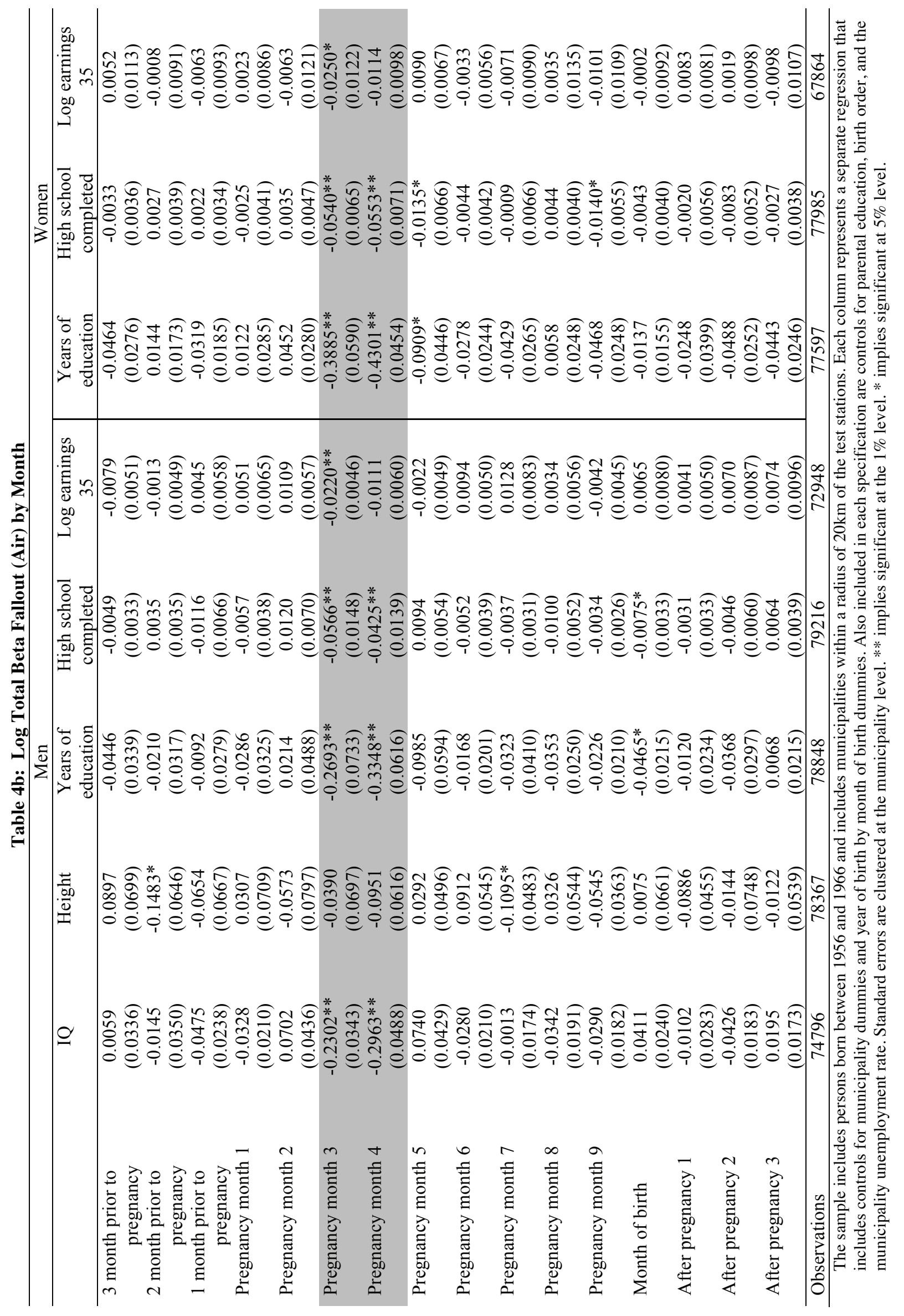




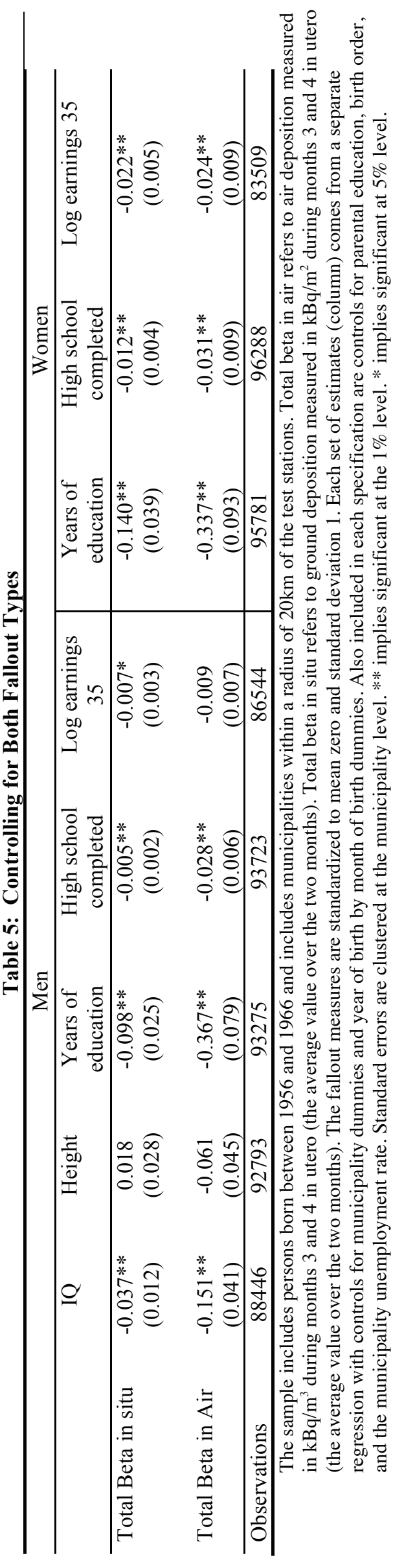




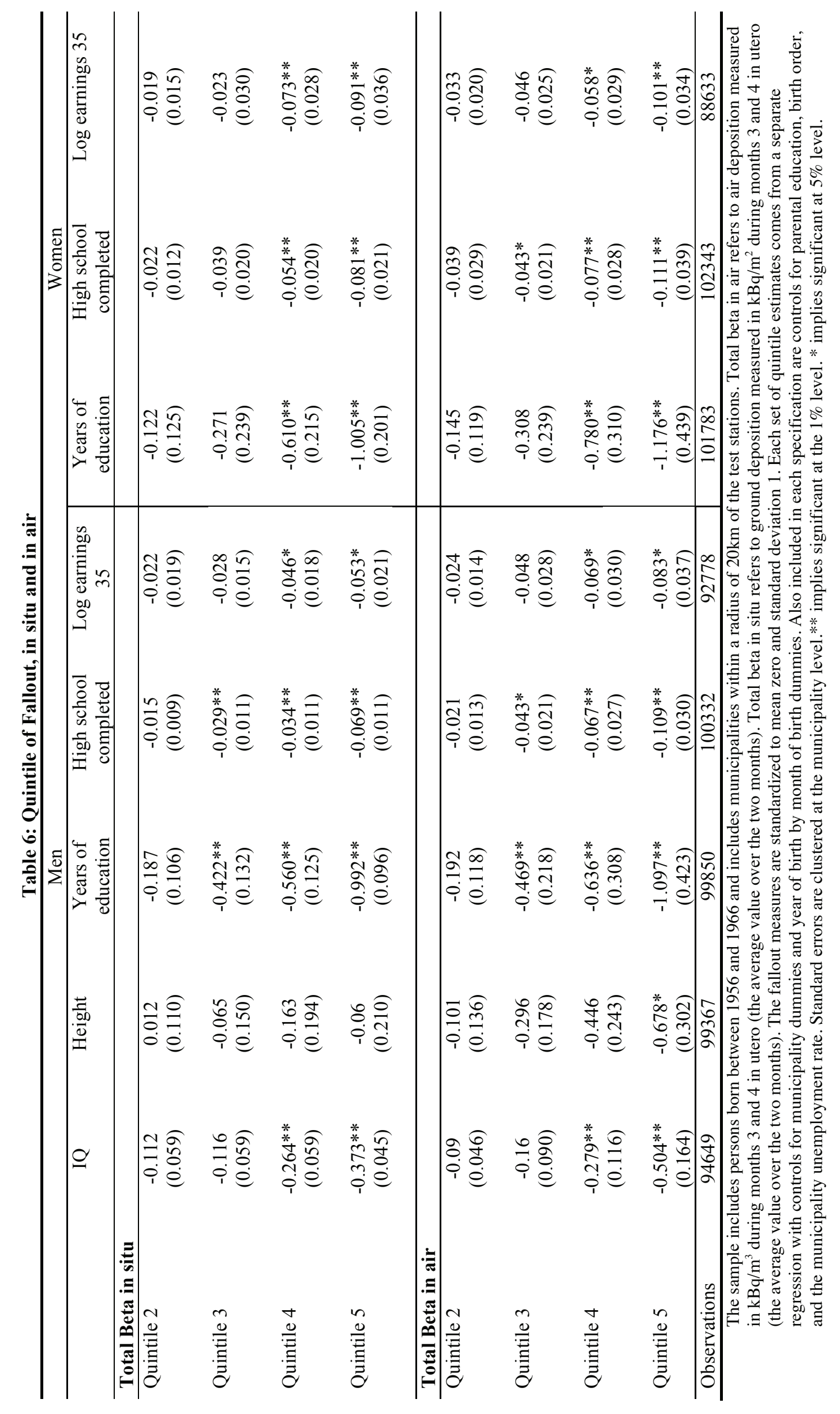




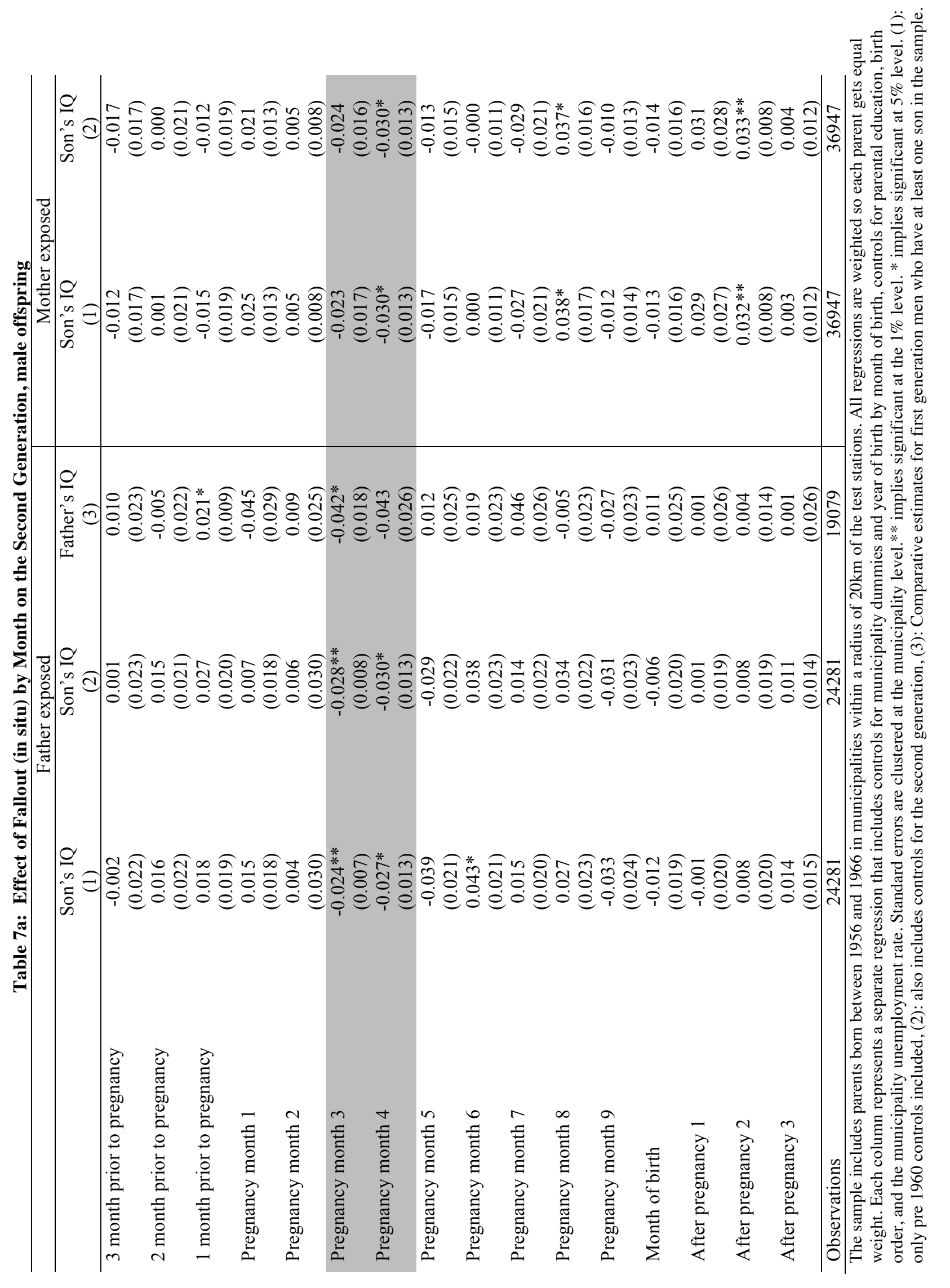




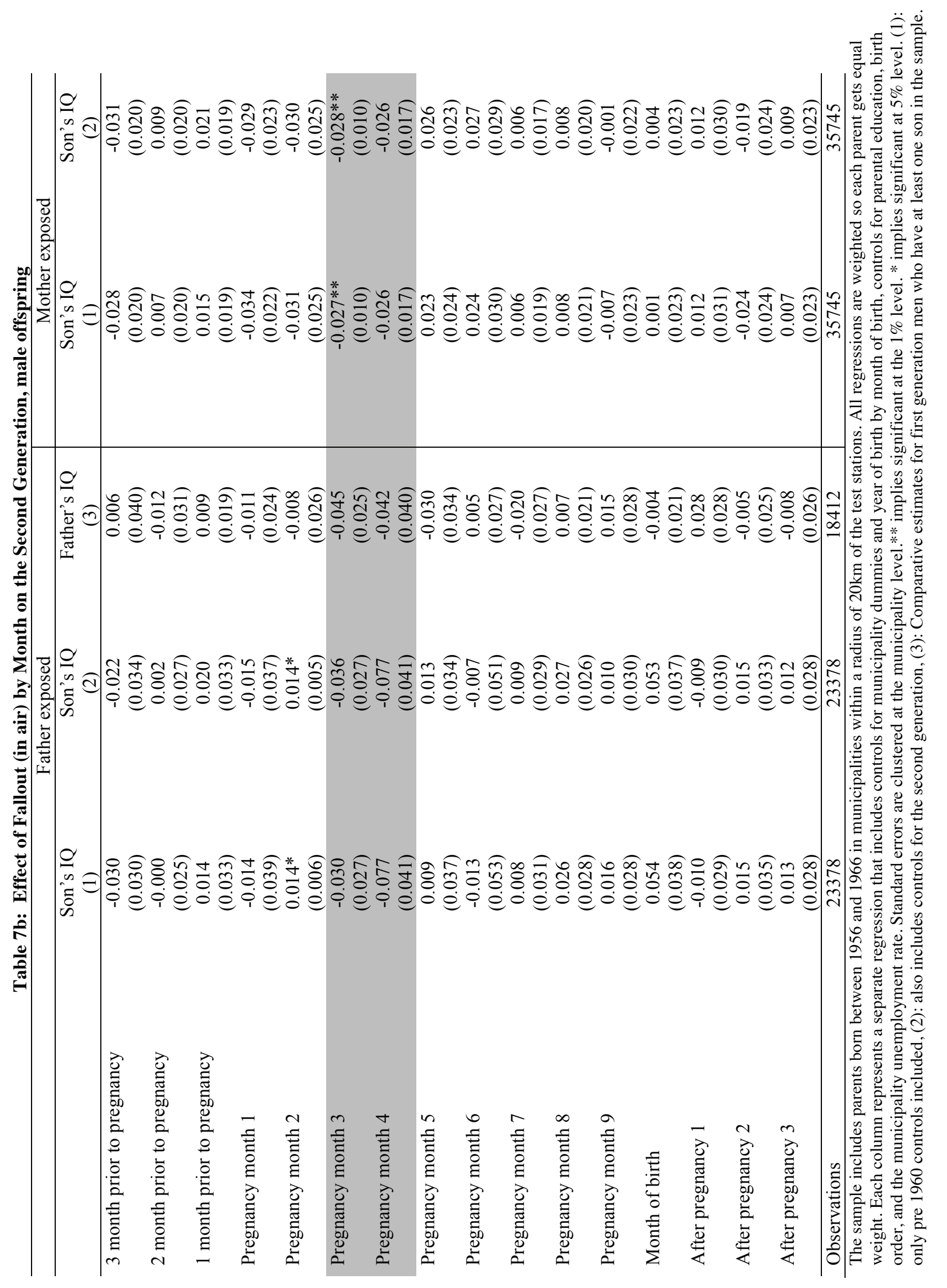




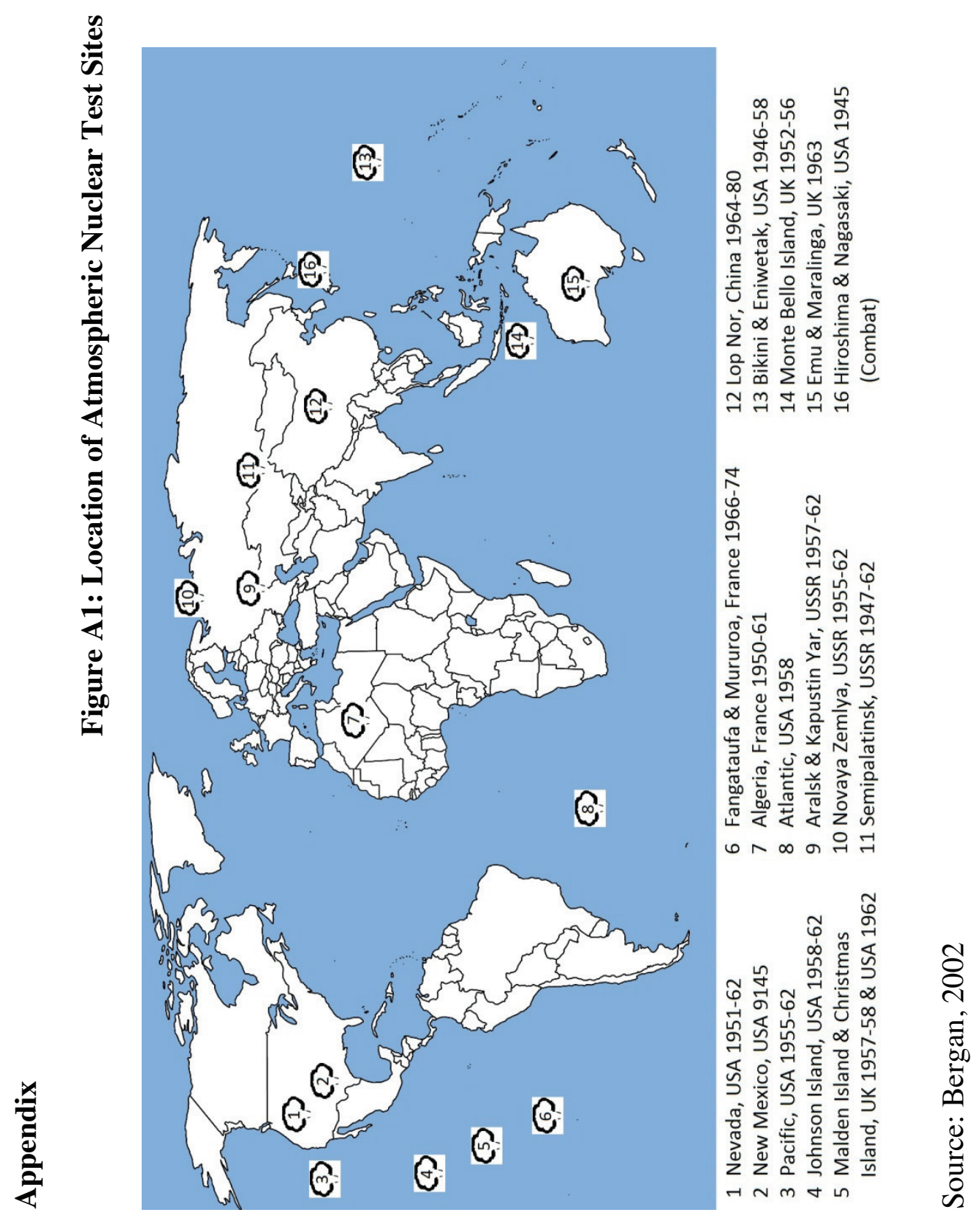




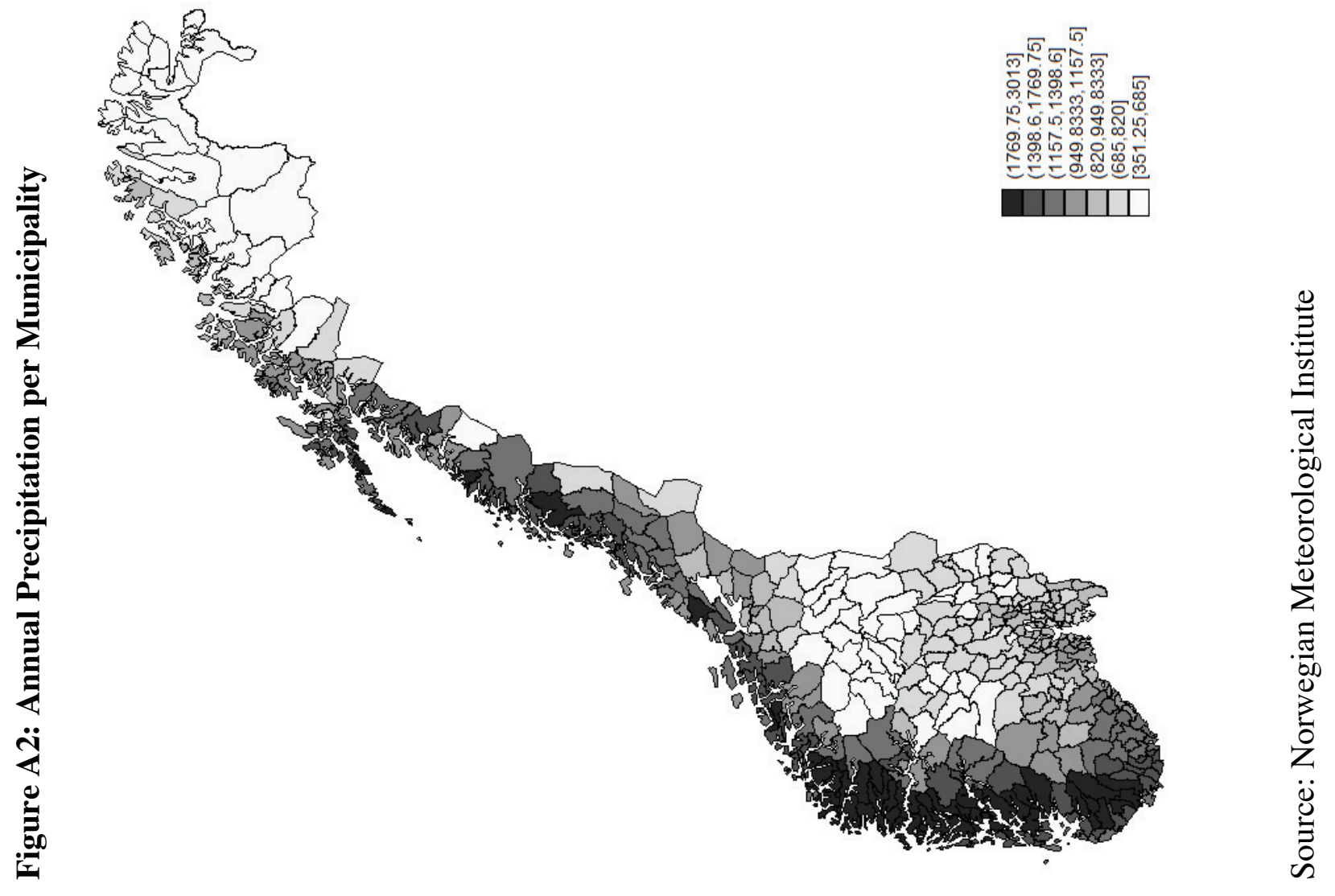




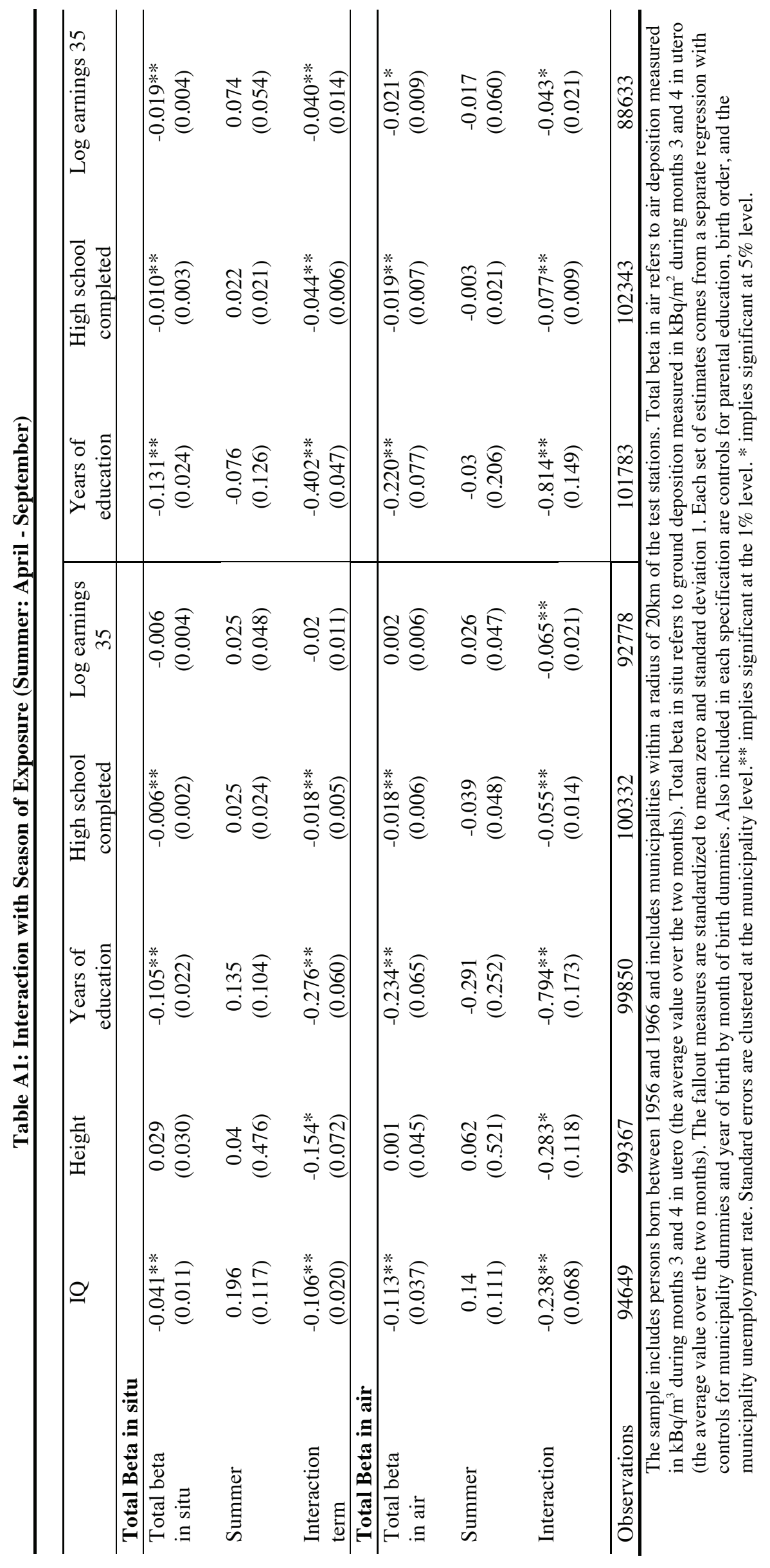




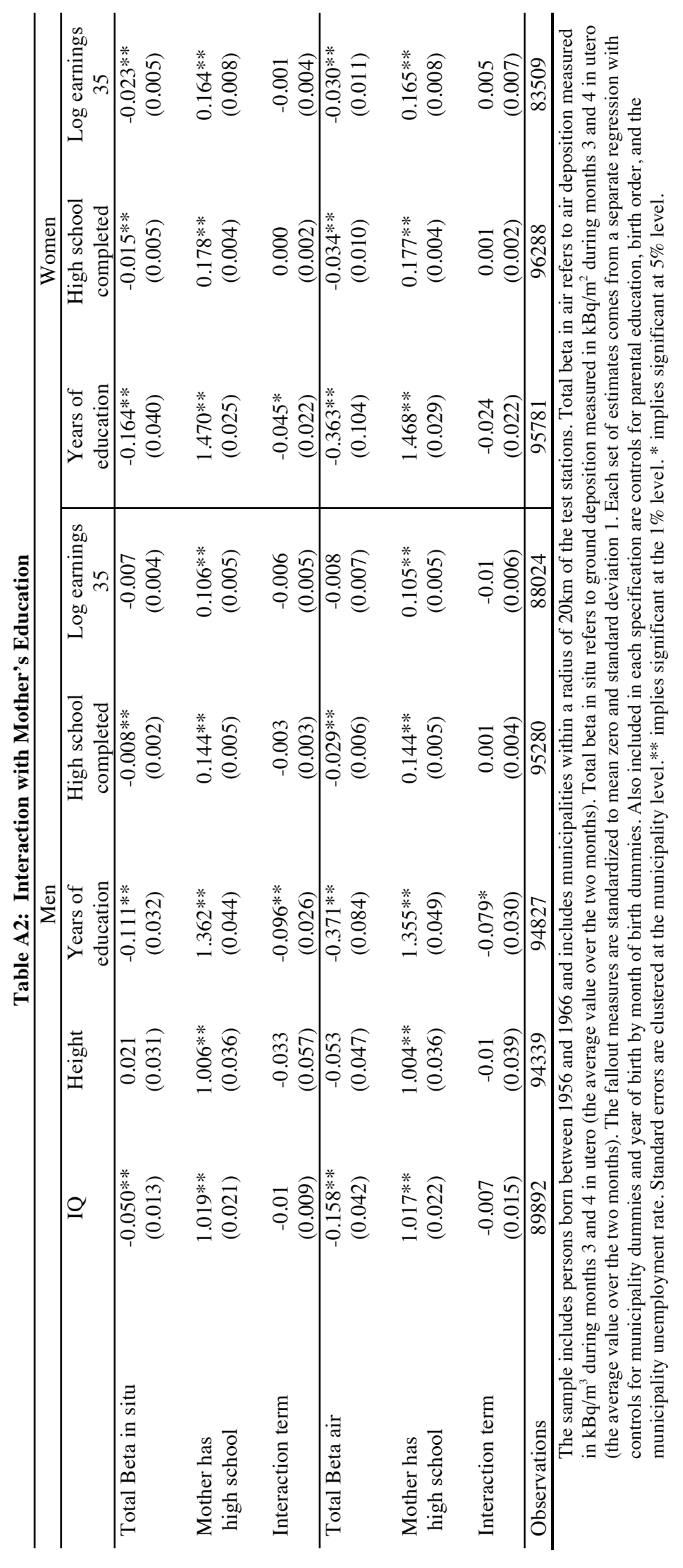




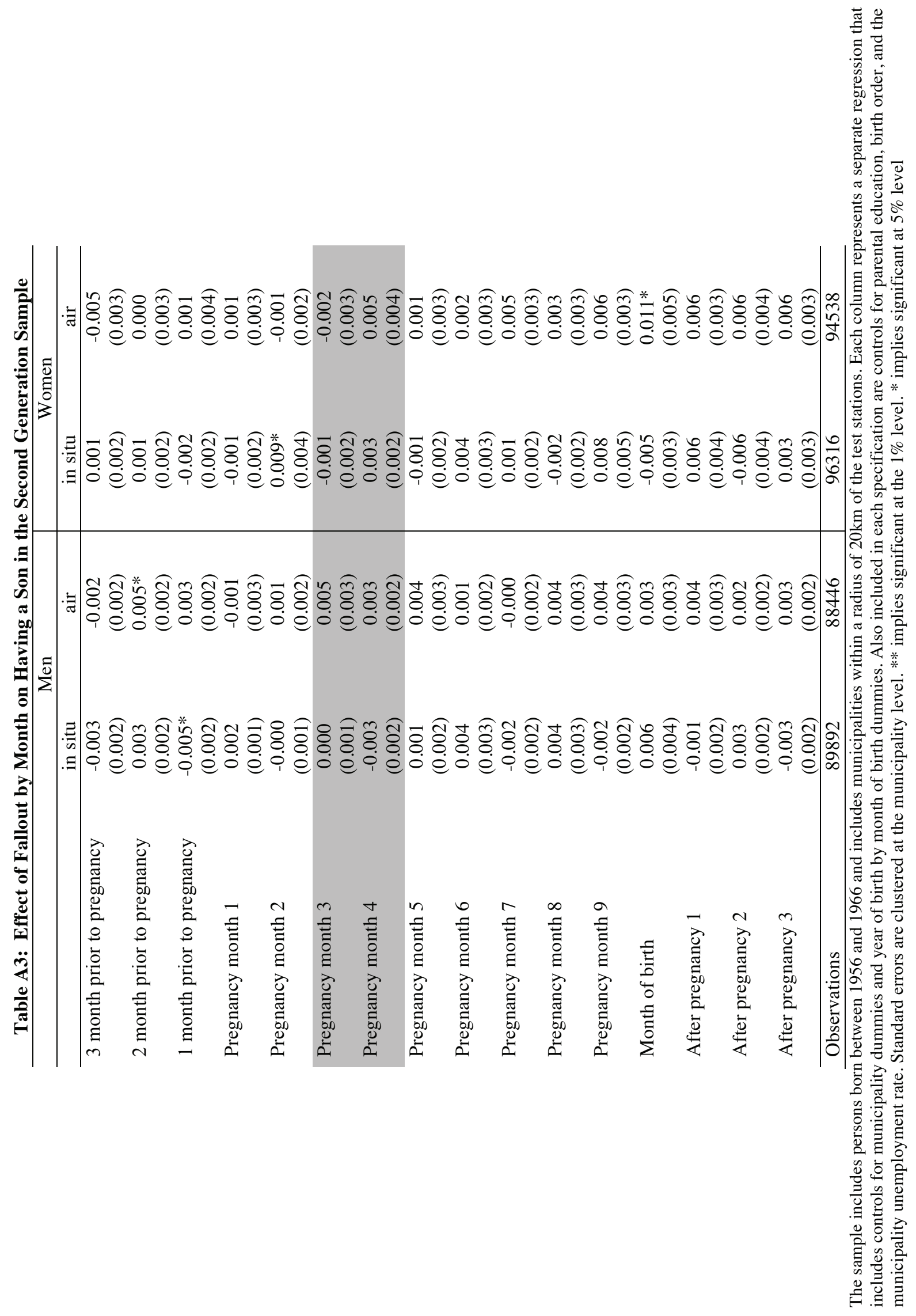

